\title{
Non-linear Analysis of the Expanding Stage in the UOE Pipe Manufacturing Process
}

\author{
Mohammad Dagdughi( ${ }^{(1)}$, Perk Lin Chong ${ }^{(2)}$, Justin Cox ${ }^{(3)}$, Sajid Abdullah(4) \\ (1) Liberty Steel Hartlepool, SAW Pipe Mills, Brenda Road, Hartlepool, TS25 2EF, UNITED KINGDOM \\ e-mail: mohammad.dagdughi@libertysteelgroup.com \\ (2) School of Computing, Engineering and Digital Technologies, Teesside University, Middlesbrough, TS1 3BX, UNITED KINGDOM \\ e-mail: p.chong@tees.ac.uk \\ (3) Liberty Steel Hartlepool, SAW Pipe Mills, Brenda Road, Hartlepool, TS25 2EF, UNITED KINGDOM \\ e-mail: justin.cox@libertysteelgroup.com
}

(4) School of Computing, Engineering and Digital Technologies, Teesside University, Middlesbrough, TS1 3BX, UNITED KINGDOM e-mail: S.Abdullah@tees.ac.uk

\section{SUMMARY}

In recent years, the increasing demand for energy has pushed oil and gas activities into more remote regions of the sea, which resulted in laying pipelines at depths greater than $2000 \mathrm{~m}$ where they are vulnerable to collapse failure. Therefore, pipes are required to be manufactured with higher circularity and thicker wall thickness, this introduces a challenge for UOE pipe manufacturers as the process will involve the application of high forces in each forming step to form the plate into a pipe, and this could affect the integrity of equipment and tools such as the mechanical expander die segments. The aim of this paper is to investigate the expansion stage in the UOE pipe manufacturing process using Finite Element Analysis (FEA). Firstly, the stresses encountered by the pipe and mechanical expander dies during the expansion stage were analysed. The study revealed that the expansion stage causes the formation of wave patterns and concavities on the pipe surfaces which results in wall thickness variation. In addition, the study showed that the pipe ovality after the expansion is between (0.034\%) and (0.055\%). Furthermore, the study revealed that the Von-Mises stresses, the mechanical expander dies experience during the expansion are about (10.26\%) lower than the pipe's yield strength. Secondly, the FEA was carried out to investigate the benefit of optimising the mechanical expander dies design on the finished pipe shape. This study showed that reducing the expander die radius by (1\%) significantly improves the pipe shape compared to the original expander die size and lowers the stress concentration on the expander dies.

KEY WORDS: $\quad$ UOE pipe; Large diameter pipe; Longitudinally welded large diameter pipes; Finite element analysis. 


\section{INTRODUCTION}

UOE pipes are used for land pipelines including the Trans-Siberia and Trans-Alaska pipelines, and recently they have been used in offshore applications [1-2]. In recent years, the demand for energy has increased, and most of the easily accessible offshore oil and gas reservoirs have been discovered and exploited [3]. This has pushed the oil and gas industry to extend their production and exploration activities into more remote regions of the sea (Deepwater or Ultrawater) regions. Consequently, it is necessary to lay pipelines in water depths greater than $2000 \mathrm{~m}$ and over longer distances than before [4-5-6]. For instance, the Blue Stream pipelines are laid at a depth of up to $2200 \mathrm{~m}$ and are used to deliver gas from Russia across the Black Sea to Turkey [7-8]. Pipelines at these depths are subjected to high external hydrostatic pressure, which poses a significant challenge for the oil and gas industry because they are vulnerable to collapse failure during installation and maintenance as they are depressurised and there is no balancing internal pressure [2-9-10]. This led to a stricter standard for pipelines [2-11]. In order to improve pipelines collapse pressure resistance, pipes need to be manufactured with tighter tolerances and higher circularity and have an outside diameter to wall thickness ratio (D/t) of less than 25 [1-12]. This in turn poses a challenge for UOE pipe manufacturers. Deepwater pipelines are thick walled pipes with a small outside diameter. Therefore, in order to increase collapse resistance, the pipe wall thickness must be increased. It is difficult to manufacture such pipes, as the process involves the application of high forces in each forming step from bending, deforming, to shaping the plate into a pipe. This can significantly influence the manufacturing equipment and tools, as it can affect the integrity of those that come in contact with the plate, such as the mechanical expander die segments [12].

UOE process setup is usually optimised by physical trial and error method by varying the process parameters, which is particularly laborious and not cost effective [11]. In recent years, the advancement in technology resulted in developing techniques such as physical experiments, detection technology, finite element analysis, and numerical simulations. These techniques have become very important for researching and optimising the UOE process [13].

Kyriakides et al. [14-15] developed a one-dimensional model of the UOE pipe manufacturing process to capture the essence of the changes in the pipe's compressive mechanical properties, which demonstrated that the pipe collapse pressure is affected by the four cold forming steps in the UOE process. Palumbo and Tricarico [11] investigated the (C-forming, U-forming, $\mathrm{O}$ forming, and Expansion) stages in the UOE process using 2D and 3D finite element method (FEM) and found that the pipe end profile is affected by the movement of the expander dies. They also showed that the strain is not uniform in the first expansion step while the transition region with a high stress value is developed in the final expansion step. Furthermore, their work revealed that the strain values become more uniform after deforming the transition region in the next expansion step [11]. In addition, Palumbo and Tricarico [11] reported that expansion is effective in correcting the pipe shape; however, the action of the mechanical expander dies has resulted in small oscillation values in the pipe radius. Herynk et al. [1] investigated the effect of the different parameters in the UOE process on the pipe geometry and mechanical properties using a 2D finite element model. They reported that expansion results in stretching some regions of the pipe more than others, and this introduces concavities on the pipe internal surface and variation in the pipe wall thickness. Furthermore, they showed that increasing the expansion ratio could improve pipe roundness and reduce its ovality and further expansion progressively reduces the pipe collapse pressure. Timms et al. [16] carried out a full-scale collapse test and coupon test to investigate the influence of the 
UOE process on the pipe's material properties and collapse pressure, they found that after expansion, the hoop tensile stress increases while the hoop compressive yield stress decreases across the pipe circumference. Han and Sun [17] simulated the UOE process using the finite element method model and reported that increasing the expansion ratio from $0 \%$ to $0.5 \%$ improves pipe ovality, but there was no significant improvement in ovality when the expansion ratio exceeds $0.5 \%$ [18]. Vathi and Karamanos [19] investigated the effect of the UOE manufacturing process and, in particular, the expansion stage on the pipe out-ofroundness and thickness variation using nonlinear finite element code. The analysis was performed on a pipe with $609.6 \mathrm{~mm}$ external nominal diameter (OD) and $32.3 \mathrm{~mm}$ wall thickness (WT). They reported that increasing the total expansion reduces the pipe ovality and improves its shape; however, excessive expansion can lead to undesirable variation in the values of pipe wall thickness. Tsuru and Agate [20] investigated the forming and buckling of high strength UOE steel pipe using the FEA model and validate the results experimentally using Minipress test apparatus with (Scale: 1/7) of the actual UOE process. They reported that the pipe ovality decreases as the expansion ratio increases. They suggested that optimising the tools in the (C-forming, U-forming, and O-forming) steps can also reduce the ovality of the pipe. Cavaliere et al. [21] presented a 3D finite element analysis to study the pipe expansion process to determine the contact pressure between the internal components in the mechanical expander. They found that the contact between the expander dies and the pipe internal surface is not restricted to the flat zone in the expander dies. Zou et al. [22] investigated the yield strength of high-strength steel in the UOE process experimentally using MT800 test machine and reported that the tensile yield strength of the pipe decreases after the (C-forming, Uforming, and $\mathrm{O}$-forming). They also reported that the expansion forming step increases and homogenizes the tensile yield strength. Furthermore, they reported that the yield strength of the pipe can be determined by the expansion ratio and wall thickness to diameter ( $t / D$ ) ratio. Kainat et al. [23] investigated the systematic imperfection in high-strength steel pipes aroused from the UOE manufacturing process using a portable 3D laser surface scanner to obtain the surface profile of the pipe and the reverse engineering technology and inspection software for the geometric analysis. Eight UOE pipes with X100 steel grade and two Electric Resistance Welding (ERW) pipes with X70 steel with (D/t) range between (64 to 103) were investigated [23]. Their work demonstrated that deviation patterns in the wave shape were present in the pipe radius and extending across the pipe length. They believed these patterns are the results of the expansion forming stage in the UOE process. Using the finite element model, Chatzopoulou et al. [18] investigated the effect of the UOE process on the structural response and resistance of offshore pipes during the installation process. The analysis was performed on a pipe with OD of $609.6 \mathrm{~mm}$ and WT of $32.33 \mathrm{~mm}$. They found that increasing hoop strain reduces the pipe ovality and improves its roundness. Furthermore, they reported that the pipe thickness after the UOE process is different from the initial plate thickness, as the mean thickness around the pipe cross-section decreases in a quasi-linear manner with the increase in expansion hoop strain [18]. Lothhammer et al. [24] investigated the residual stress in two pipe samples manufactured by the UOE and ERW processes. They found that the longitudinal and circumference stresses in the hole were compressive in the first half and tensile in the second half. Additionally, their work revealed that the distribution of the circumferential stresses for the internal and external surface are parallel, and the longitudinal stresses cross them at around half the hole depth. They suggested that the longitudinal stresses are influenced by the $U$ and $O$ stages, while the circumference stresses are affected by the expansion stage. Using the finite element method Delistoian and Chirchor [25] investigated the 
Von-Mises stresses in each forming step of the UOE manufacturing process to analyse a steel plate (Length $=30 \mathrm{~mm}$, Width $=1250 \mathrm{~mm}$, and $W T=7.9 \mathrm{~mm}$ ) with X65 material. They reported that there is a region characterised by high-stress concentration that appears in the pipe body after the 0 -forming stage. Additionally, they reported that after the expansion stage, the stress distribution becomes uniform. However, the region with the high stresses remains in the pipe for all its service life.

Most of the works in the previous publications have involved modelling the mechanical expander dies as analytical rigid surfaces or discrete rigid bodies. This does not provide a clear understanding of the effect of the expansion stage on the mechanical expander dies during the expansion operation. In the current paper, a Nonlinear Finite Element Analysis is performed using $\mathrm{NX}^{\mathrm{TM}}$ software, version 10, Advanced Simulation, to simulate the final stage (Expansion stage) in the UOE pipe manufacturing process. The aim of the study is to investigate the effect of the final stage (Expansion stage) in the UOE pipe manufacturing process on the final pipe geometry and mechanical expander dies integrity.

\section{DESCRIPTION OF UOE PIPE MANUFACTURING PROCESS}

UOE pipe manufacturing process is one of the most common methods used to manufacture longitudinally welded large diameter pipes [8-26]. The process was originally developed by Kaiser Steel Corporation in California [2], and today, more advanced versions of the UOE process are found in Europe, the USA, South America, and Japan [2]. UOE is an automated process that involves forming steel plates into pipes using four main cold forming steps. The first forming step is C-forming; the plate longitudinal edges are bent into circular arcs between two involute-shaped dies in the edge crimping machine [1-27]. The second forming step is the U-forming; the C-shaped plate is placed on two side rollers, then bent through three-point bending by moving the U-punch downward in the vertical direction, the U-punch is then held in position, and the plate is further bent into the U-shape or "skelp" by the side rollers as they travel inward in the horizontal direction [1-2]. The third forming step is the O-forming; the Ushaped plate is pressed into an open-seam pipe by two semi-circular dies in the 0-press machine [2-28]. The open-seam pipe is then passed to the multi-wire Submerged Arc Welding machines (SAW) where it is first welded from the inside along the entire length and then welded from the outside [2-28]. The final forming step is expansion; the expander die segments are inserted into the welded pipe, then they are hydraulically moved outward in radial direction and the pipe is stretched in the hoop direction [2-11].

\section{DESCRIPTION OF UOE PIPE MANUFACTURING PROCESS}

The final forming step is expansion; the pipe is expanded using the mechanical expander, as shown in Figure 1. Typically, a mechanical expander consists of 8, 10, or 12 die segments [1-2]. These dies are mounted around the expander cone which is fixed to a hydraulic cylinder pull rod. Expansion is achieved by inserting the expander head inside the pipe, and then actuating the hydraulic cylinder to move the expander cone in the horizontal direction. This results in moving the die segments outward in the radial direction to expand the pipe while a lubricant is applied to the dies simultaneously [2-11-29]. Expansion is performed to give the pipe its final shape by reducing its ovality and improving its roundness [1]. 


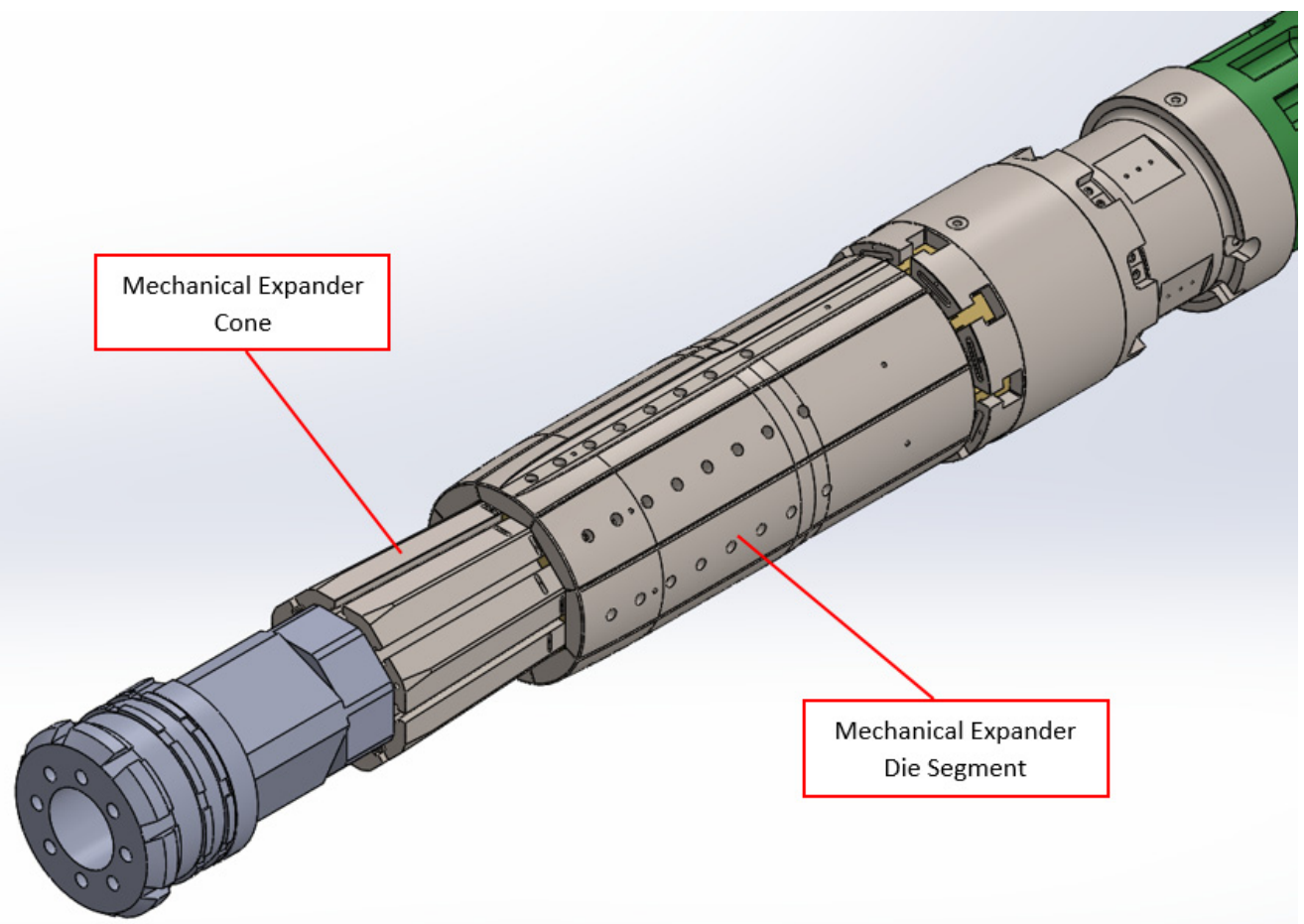

Fig. 1 CAD model of the mechanical expander

\section{FINITE ELEMENT ANALYSIS OF THE EXPANDING FORMING STAGE}

Finite element analysis (FEA) is an important tool that has been used previously to investigate the UOE process. FEA is a useful and powerful numerical method widely used to solve many mathematical physics and engineering problems [30-31]. The current study consists of two FEA studies. The first study aims to investigate the effect of the expansion stage in the UOE pipe manufacturing on the finished pipe shape and the stress distribution in the pipe and mechanical expander die segment during the expansion operation. The second study aims to investigate the benefit of optimising the mechanical expander dies design on the finished pipe shape.

\subsection{FIRST 3D FEA (PIPE EXPANDED INCREMENTALLY)}

For the FEA of the expansion stage in the UOE process, Nonlinear Finite Element Analysis simulations were developed using Siemens NX10 Advanced Simulation software. In this paper, an approach similar to Raffo et al. [32] was adopted by choosing the implicit solution 601 since it can use larger time steps, and selecting the (SOL 601,106 Advanced Nonlinear Statics) solver to account for the geometric nonlinearity and material plasticity.

The FEA is based on the production parameter of pipe with $(O D=20 \mathrm{in}, W T=1 \mathrm{in}$, and Material = API X65), due to the complexity of the expansion stage in the UOE manufacturing process, the expansion process was simplified by adopting a cost-effective approach to reduce computational power and time as illustrated in Figure 2 [11]. Therefore, only the pipe and mechanical expander die segments were considered in the current study. The pipe geometry was model by considering the pipe cross-section after the O-forming step and prior to the expansion step "UO pipe", the cross-section is modelled oval, the horizontal 
diameter is $2 \mathrm{~mm}$ greater than the vertical diameter, the pipe cross-section was then extruded $1 \mathrm{~m}$ along a straight line. In the analysis, the approach adopted is similar to that of Cavaliere et al. [21] as the weld seam is neglected to simplify the pipe model. Mechanical expander die segments were model based on actual production data provided by Liberty Steel, the overall dimension of each die is length of $930 \mathrm{~mm}$, height of $86.5 \mathrm{~mm}$, and width of $132.6 \mathrm{~mm}$.

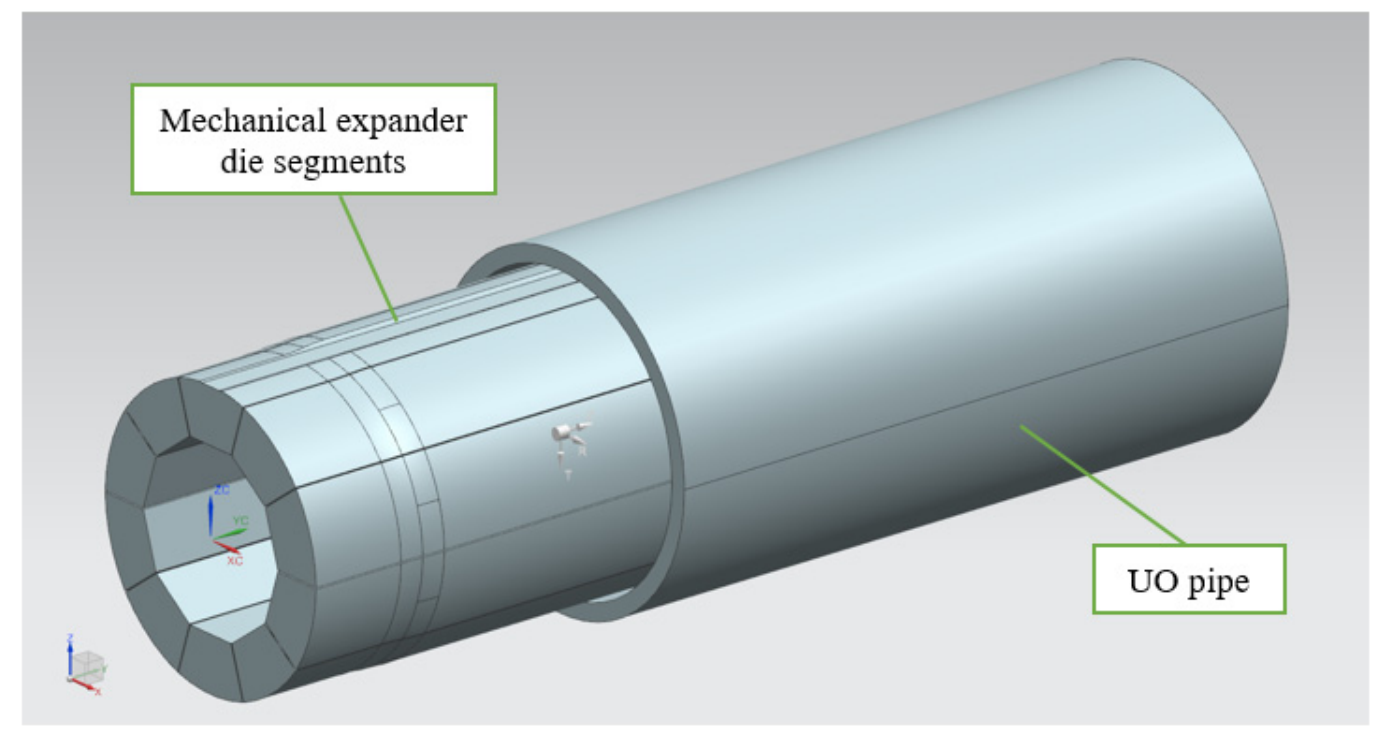

Fig. 2 UO pipe and mechanical expander die segments geometries

(C) Siemens 2019. Reprinted with permission

Since the aim of the study is also to investigate the stress distribution on the mechanical expander die segments, mechanical expander dies were not modelled as analytical rigid surfaces or discrete rigid bodies as considered in previous publications. Both the pipe and mechanical expander die segments geometries are meshed using 3D swept mesh with CHEXA (8) element type, as the pipe consists of thin geometry with a uniform cross-section, and the geometries of the expander dies have less variation.

The material for the UO pipe was modelled by creating an isotropic material using the American Petroleum Institute (API) X65 steel with the mechanical and physical properties shown in Table.1. A stress-strain hardening is developed in the isotropic material to simulate its nonlinear behaviour (Pipe deformation in loading condition, and pipe spring back in unloading condition). The true stress-strain curve for API X65 steel used in the current work has been adapted from Liu et al. [33], and the isotropic hardening rule was used because the load is applied in one direction (Radial direction).

Table 1 Mechanical and physical properties for APL X65 steel [33]

\begin{tabular}{ccccc}
\hline $\begin{array}{c}\text { Young's modulus } \\
(\mathrm{MPa})\end{array}$ & $\begin{array}{c}\text { Poisson's } \\
\text { ratio }\end{array}$ & $\begin{array}{c}\text { Yielding strength } \\
(\mathrm{MPa})\end{array}$ & $\begin{array}{c}\text { Tensile strength } \\
(\mathrm{MPa})\end{array}$ & $\begin{array}{c}\text { Density } \\
\left(\mathrm{kg} / \mathrm{m}^{3}\right)\end{array}$ \\
\hline $210.7 \times 10^{3}$ & 0.3 & 464.5 & 563.8 & 7850 \\
\hline
\end{tabular}

The material for the mechanical expander die segments was modelled by creating an isotropic material using chromium-molybdenum nitriding (EN40B) steel [34], the values of the yield strength and ultimate tensile strength were given as $585 \mathrm{MPa}$ and $775 \mathrm{MPa}$ respectively [34]. 
During the simulation of the expansion stage in the UOE process shown in Figure 3, the expander dies segments are positioned in the middle of the UO pipe, and a cylindrical constraint boundary condition is applied to the pipe external surface to allow the pipe to expand in the radial direction during an expansion operation. An enforced displacement constraint boundary condition has been applied to the mechanical expander die segments, and eleven-time increments were created to perform four expansion steps (Loading/Unloading).

In the first step, the expander dies are moved outward radially to expand and deform the pipe (Loading); in the second, inward radially to calculate the pipe spring back (Unloading); in the third, forward in the Y-direction inside the pipe to position the expander dies for the next expansion step (Loading/Unloading). Then, the simulation follows similar patterns from step four to step eleven. The contact between the pipe internal surface and the expander dies external surfaces are defined using surface to surface contact boundary condition type, and the coefficient for static friction is assumed to be 0.1 [35] to account for the lubricant between the pipe and expander dies.

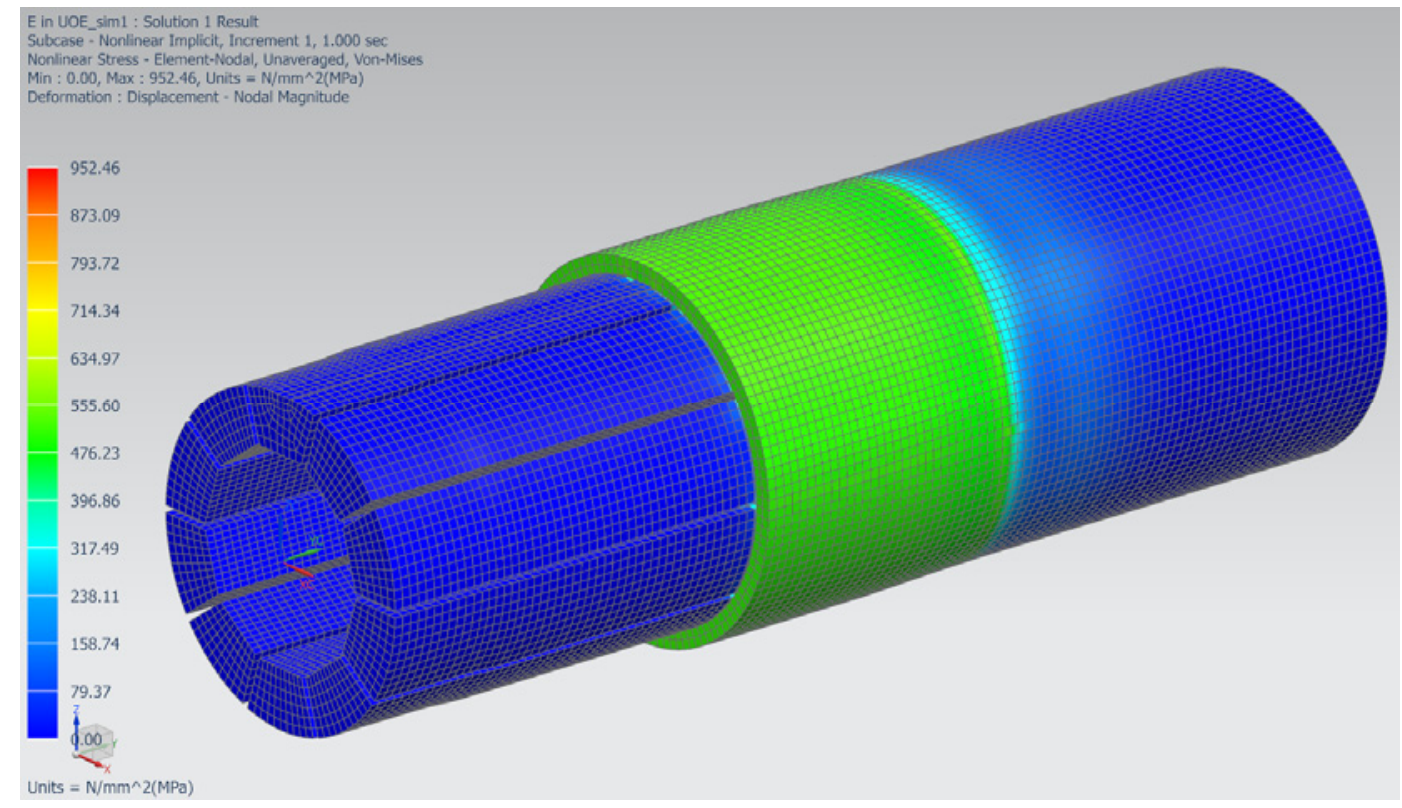

Fig. 3 FEA of the expansion operation

(C) Siemens 2019. Reprinted with permission

\subsection{RESULTS}

\subsubsection{EFFECT ON PIPE SHAPE}

After the four expansion steps, FEA displacement results showed that the finished pipe shape is affected by the expansion operation and the deformation in the pipe is not uniform across the circumferential direction and along the longitudinal direction. 


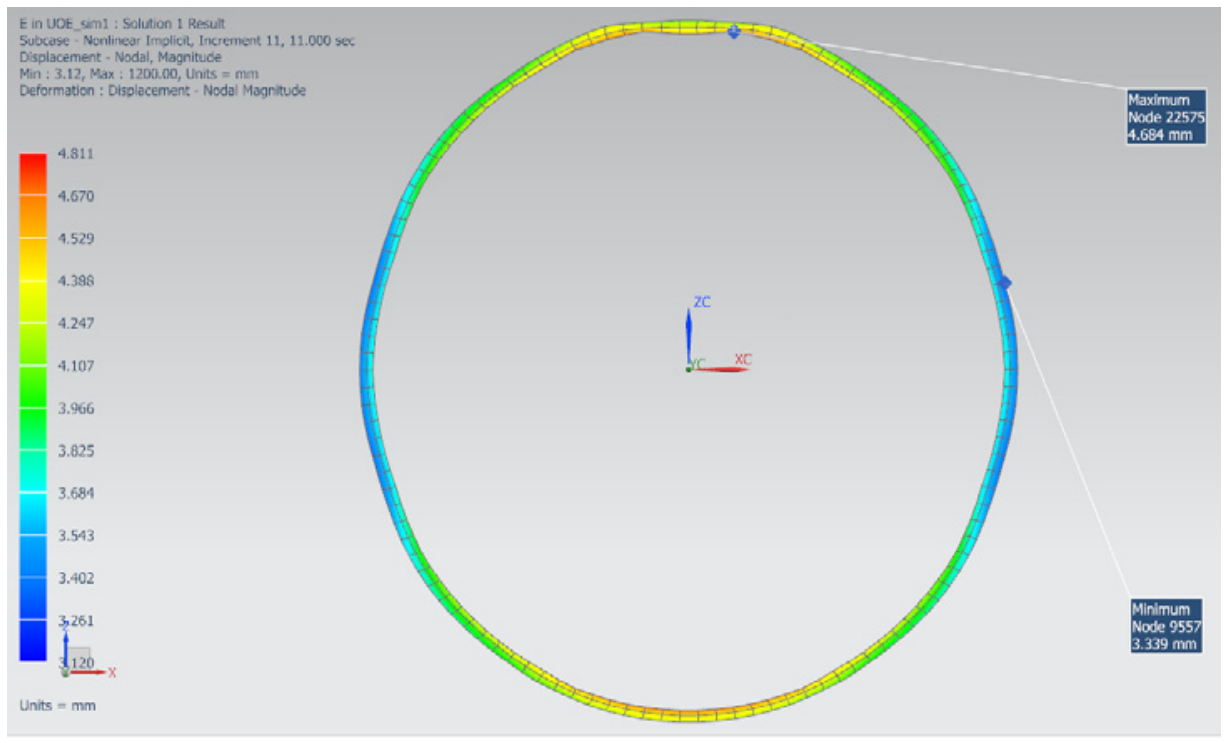

Fig. 4 Pipe cross-section

(C) Siemens 2019. Reprinted with permission

Figure 4 represents the displacement across the pipe circumference, and the results show that the maximum displacement in the regions measured was $4.684 \mathrm{~mm}$, and the minimum displacement was $3.339 \mathrm{~mm}$. FEA also showed that after the expansion operation, the pipe OD in the vertical direction is $508.245 \mathrm{~mm}$, and the pipe OD in the horizontal direction is 508.676 $\mathrm{mm}$. The initial ovality in the pipe is calculated using Eq. (1):

$$
\Delta_{0}=\frac{\left(D_{\text {Max }}-D_{\text {Min }}\right)}{\left(D_{\text {Max }}+D_{\text {Min }}\right)} \times 100
$$

Where: $\Delta_{0}$ is the initial ovality in the pipe (\%), $D_{\text {Max }}$ is the maximum diameter $(\mathrm{mm})$, and $D_{\text {Min }}$ is the minimum diameter $(\mathrm{mm})$ [1].

Pipe ovality is one of the important imperfections that can affect the pipe collapse pressure [1]. In Eq. (1), the initial ovality in the pipe was determined to be $0.0424 \%$. This ovality value is low compared to the UO pipe which shows that the expansion operation helps in reducing out of roundness of the pipe and correcting its shape [2-11].

Figure 5 illustrates the results obtained for the wall thickness across the pipe circumference. Wall thickness was determined using a sufficiently appropriate dense number of points across the pipe circumference. From Figure 5, the maximum wall thickness is found to be $25.061 \mathrm{~mm}$ which is $1.33 \%$ lower than the ideal wall thickness, and the minimum wall thickness is 24.907 $\mathrm{mm}$, this is $1.94 \%$ lower than the ideal wall thickness. 


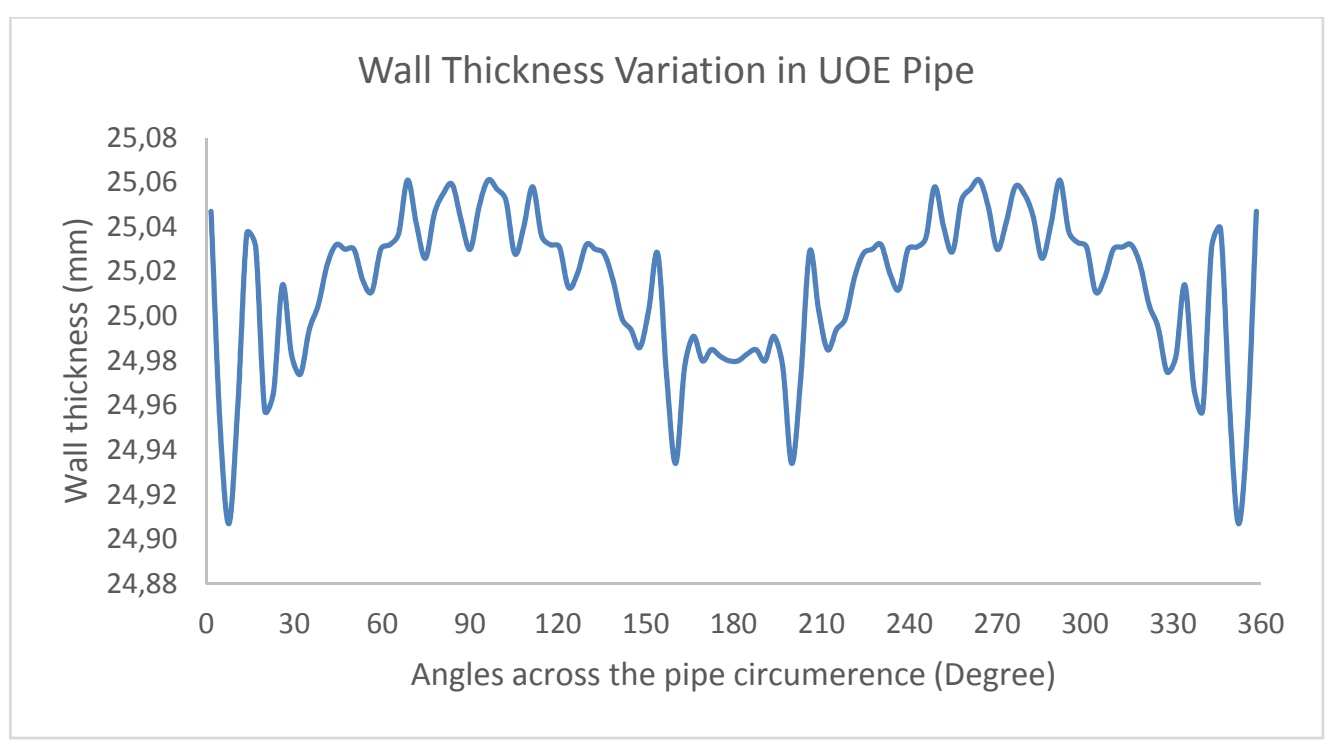

Fig. 5 Wall thickness variation in UOE pipe

Figure 4 shows that the expansion operation resulted in the formation of concavities like the ones reported by Herynk et al. [1], these concavities are formed on the pipe internal surface, and across the circumference. Their location is consistent with the regions that come in contact with the expander dies [1]. Wave patterns also formed like the ones reported by Kainat et al. [23]. These patterns are formed on the pipe external surface across the circumference and extend along the longitudinal direction [23]. These patterns and concavities are more pronounced in the horizontal direction and their formation on the pipe introduces variation in the pipe wall thickness, as illustrated in Figure 5.

Patterns and concavities are formed on the pipe surfaces by the action of the expander dies. During expansion, expander dies act on different regions of the whole pipe circumference, This results in a discontinuity in the load distribution as some regions are not in contact with the dies. This, in turn, causes the pipe cross-section to stretch and deform unevenly across its circumference.

Figure 6 represents the displacement across the pipe length. The results show that the maximum displacement in the whole pipe is $4.811 \mathrm{~mm}$, and the minimum displacement is $3.120 \mathrm{~mm}$. Figure 6 signifies that after the expansion operation, the pipe is characterised by oscillations across the length. These oscillations are formed by the mechanical expander which expands the pipe in steps. After expanding the pipe in the first step, the expander dies are moved forward inside the pipe. However, the dies maintain some overlap between the expanded regions and unexpanded regions of the pipe. This results in deforming the overlapped regions twice and the process is repeated during the expansion operation [2]. Subsequently, these overlapped regions produce uneven deformation across the pipe length which causes oscillations on the pipe surfaces. 


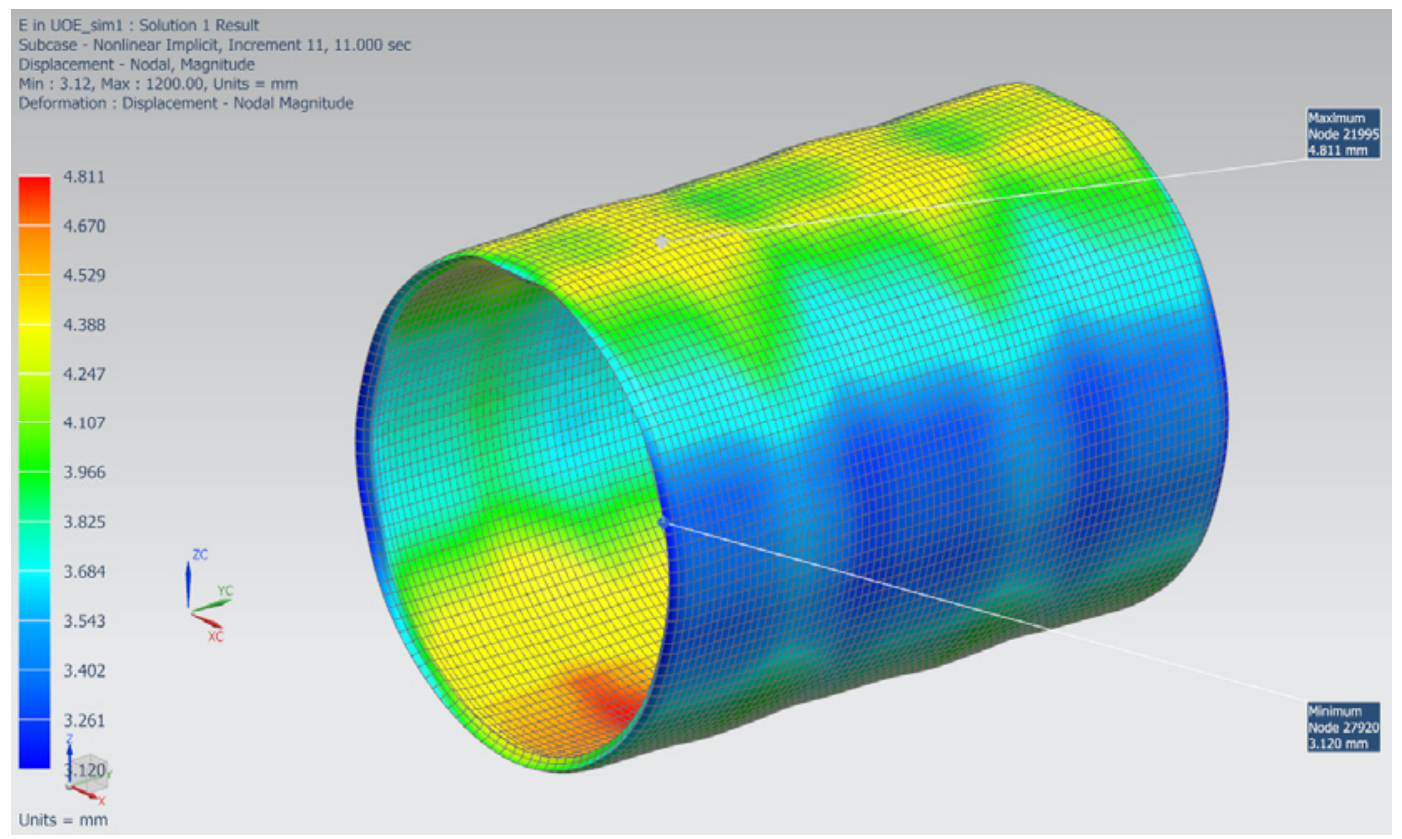

Fig. 6 Displacement results across the pipe length (Right view)

(C) Siemens 2019. Reprinted with permission

FEA results revealed that after expansion operation, there is fluctuation in the values of the pipe ovality across the length, as demonstrated in Figure 7. From Figure 7, the maximum ovality value is $(0.055 \%)$, and the minimum ovality value is $(0.034 \%)$. Figure 7 indicates that the highest ovality values are located at both pipe ends. This indicates that the repeated action of the expansion operation affects the pipe end profile, which agrees with Palumbo and Tricarico [11]. Furthermore, Figure 7 shows that the lowest ovality value occurs at the overlapped region.

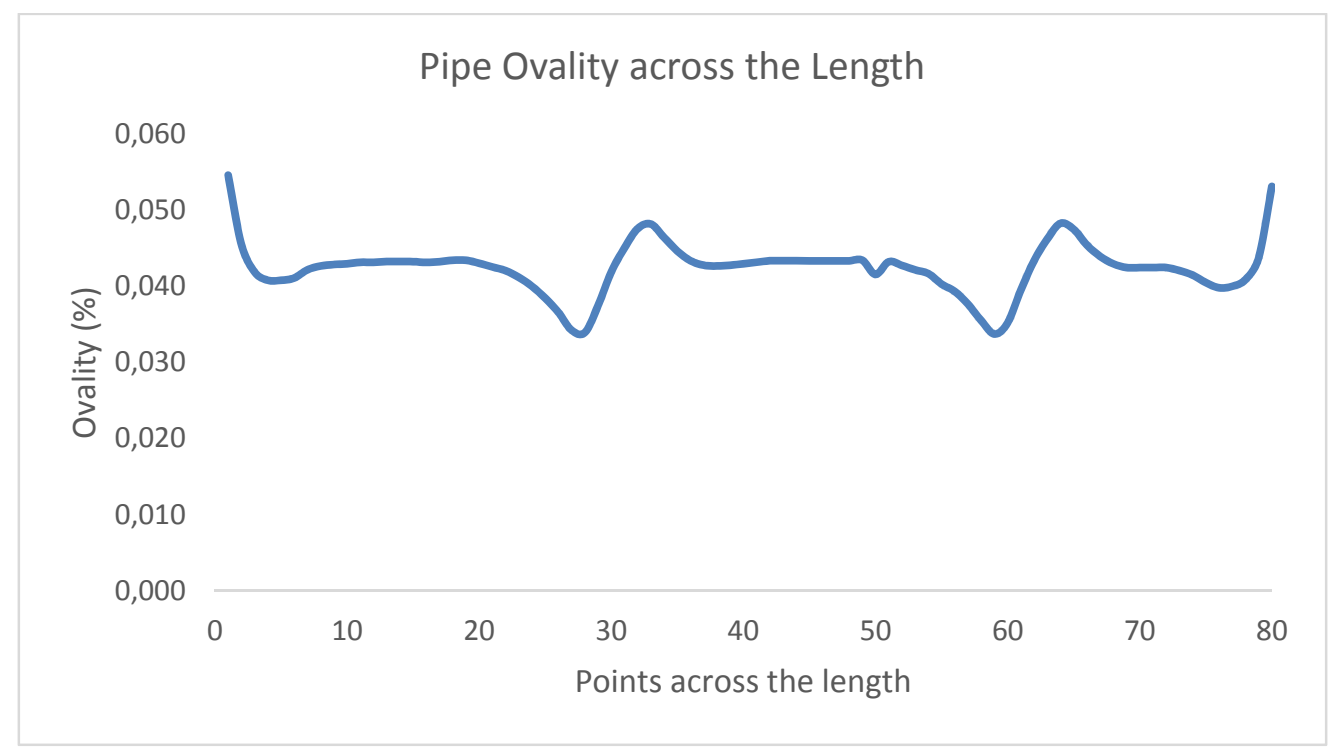

Fig. 7 Ovality across the pipe length 


\subsubsection{STRESSES IN PIPE}

Figure 8 shows the Von-Mises stress distribution across the pipe circumference after the first expansion step (Loading/Unloading). The results show that the stresses are not uniform in the longitudinal direction as the expander dies only expand a small section of the whole pipe at the time. The maximum Von-Mises stress value was $541.99 \mathrm{MPa}$ after the first expansion step. The stress values then decrease and suddenly drop to zero as they approach the regions near the regions deformed by the expander dies, as shown in Figure 8a. Additionally, since the expander dies only acts on different regions of the pipe internal surface rather than the whole pipe circumference, the stress distribution in some regions across the pipe circumference is discontinuous, as shown in Figure 8b [11].

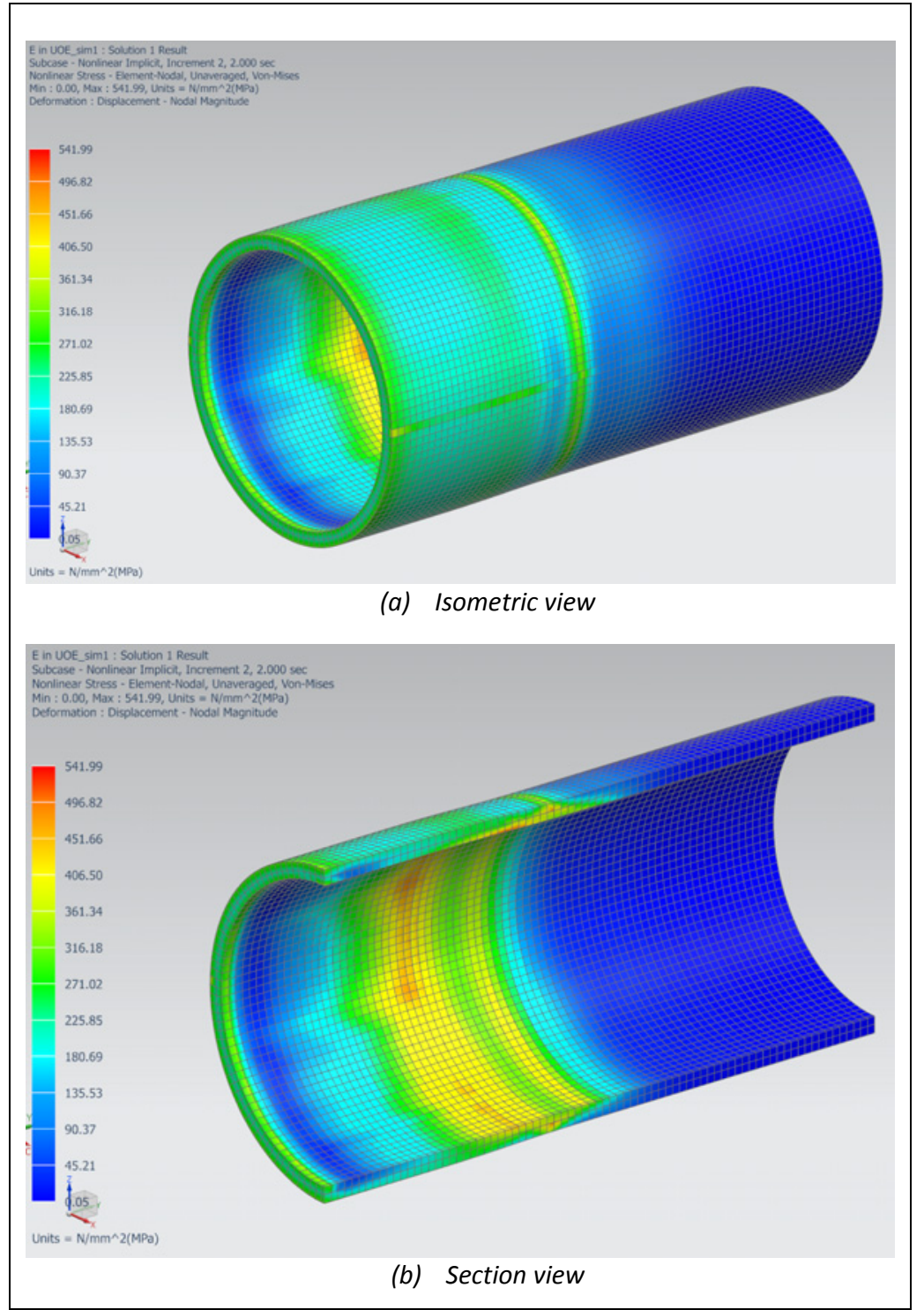

Fig. 8 Von-Mises stresses in the pipe after the first expansion step

(C) Siemens 2019. Reprinted with permission

Furthermore, FEA results signify that a critical region known as the transition region is developed in the pipe after the first expansion step, which is similar to the findings of Palumbo 
and Tricarico [11]. The transition region is located at the end of the first expansion step near the one deformed by the expander dies and characterised by the highest stress value in the pipe, as illustrated in Figure 8b [11]. The maximum stress in this region is found on the internal surface with a value of $541.99 \mathrm{MPa}$. The stress values decrease up to about (406.5 $\mathrm{MPa}$ ), as the stress approaches the external surface.

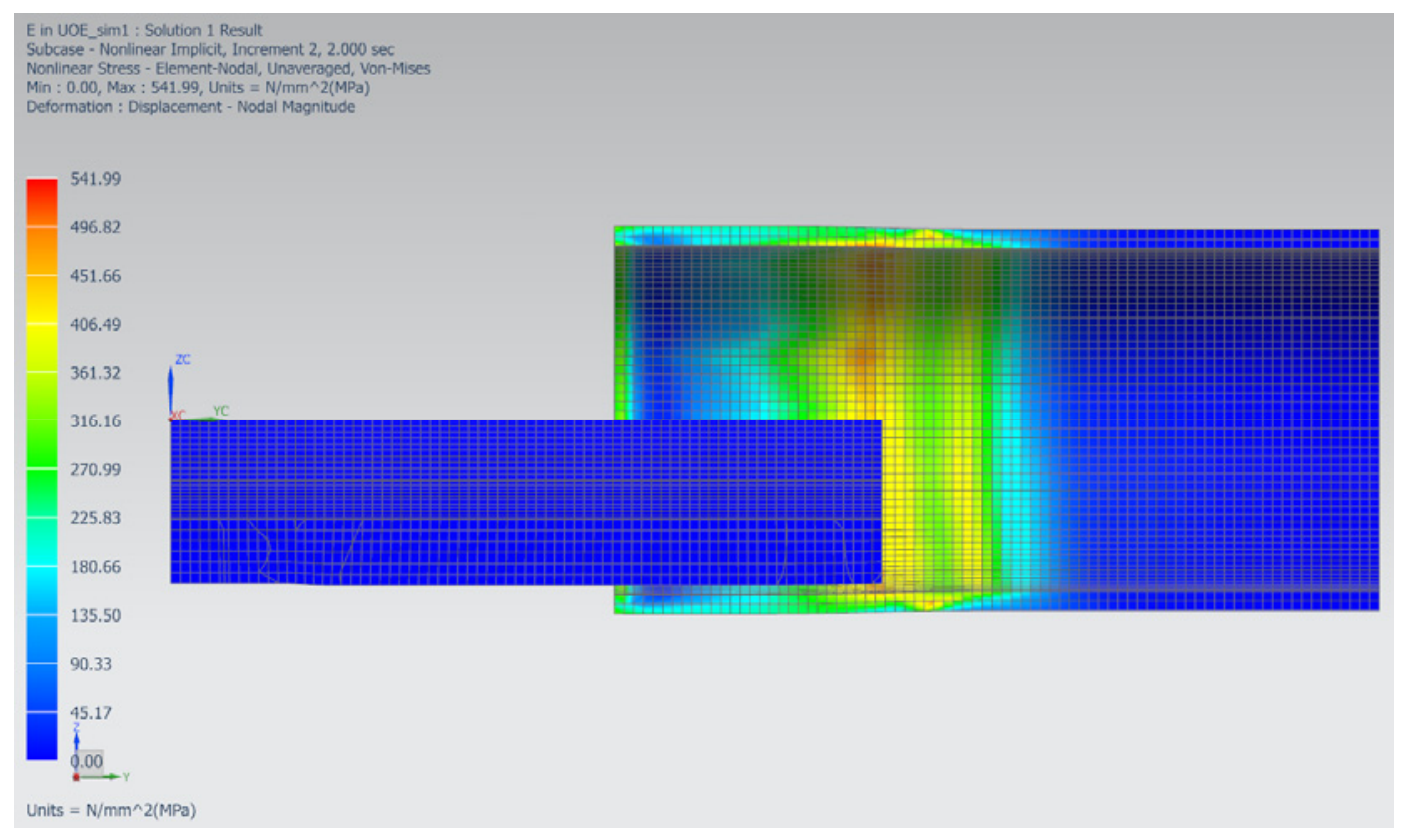

Fig. 9 Transition region in the first expansion step

(C) Siemens 2019. Reprinted with permission

Mechanical expander dies result in the formation of the critical region, as demonstrated in Figure 9. The pipe at this region is affected by the end of the front section Nose Zone, as shown in Figure 10. This results in high-stress concentration during expansion as the unexpanded region of the pipe tries to resist the plastic deformation, as shown in Figure 9. The high-stress values could be due to the simplification made in die design as fillets were neglected.

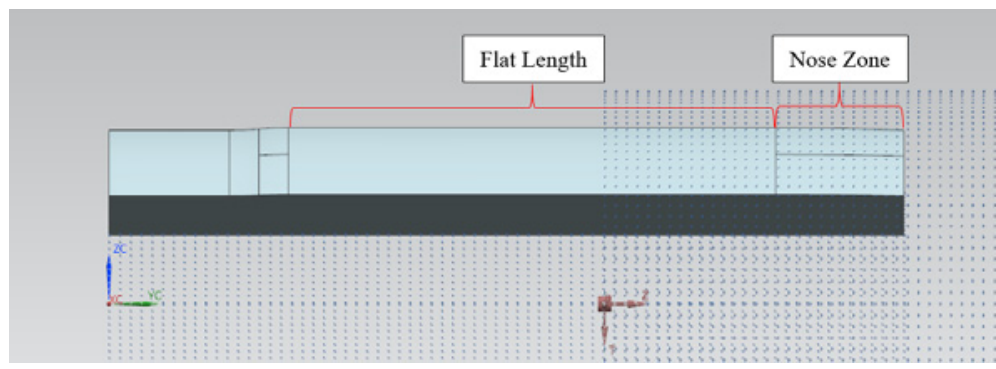

Fig. 10 Mechanical expander die sections [21]

(C) Siemens 2019. Reprinted with permission

As shown in Figure 11, after the second expansion step, the previous transition region is further deformed by the expander dies, resulting in more uniform plastic deformation which reduces and redistributes the high-stress distribution in this region, similarly to what Palumbo and Tricarico [11] reported. The average Von-Mises stress in the deformed section of the pipe 
is found to be about 263.085 $\mathrm{MPa}$. In addition, a new transition region is developed after the second expansion step located at the end of the second expansion step near the region deformed by the expander dies, as illustrated in Figure 11b. The maximum stress in this region is about $543.75 \mathrm{MPa}$ on the internal surface and $422.13 \mathrm{MPa}$ on the external surface.

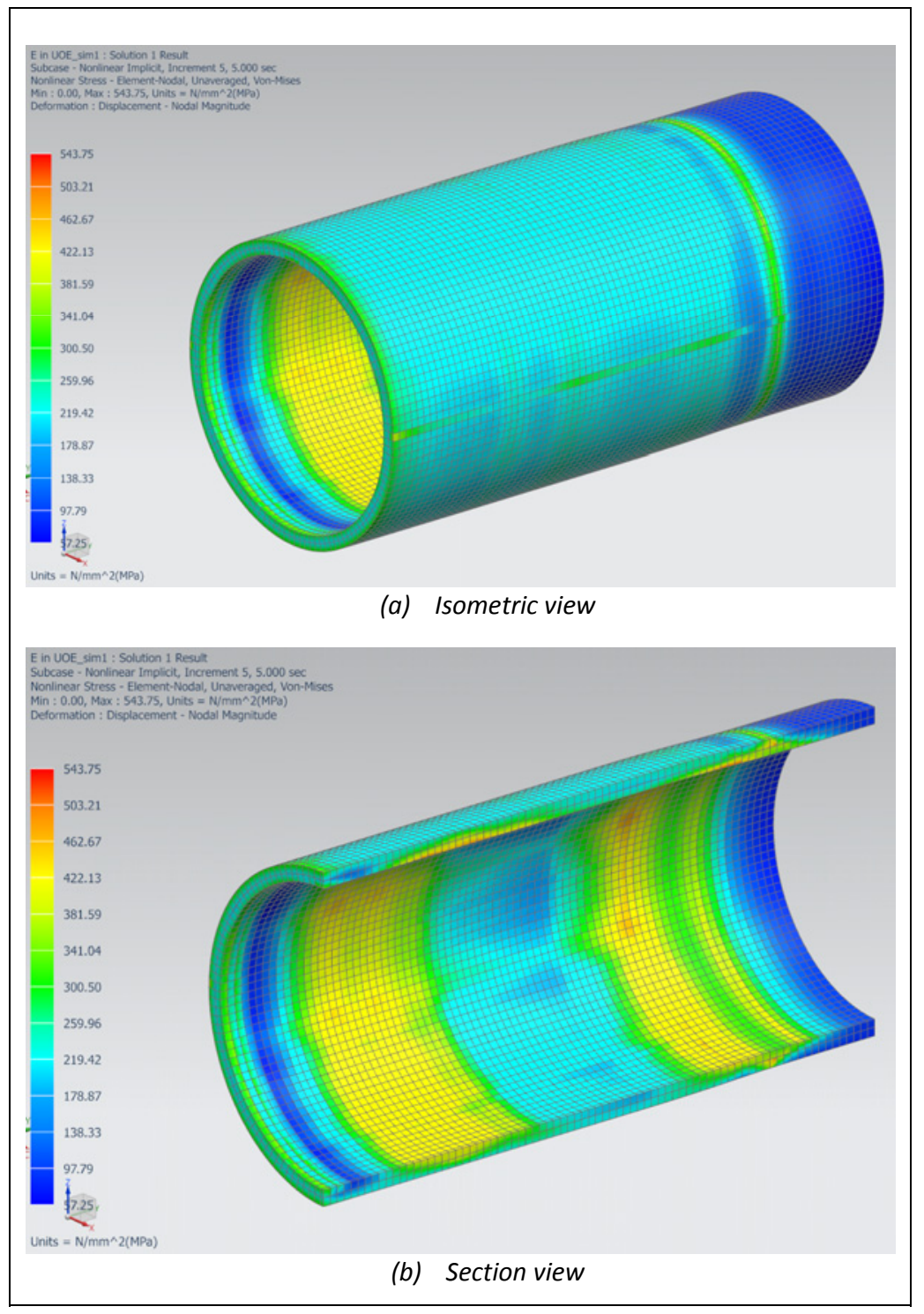

Fig. 11 Von-Mises stresses in the pipe after the second expansion step

(C) Siemens 2019. Reprinted with permission

After the third expansion step, the transition region from the second step is further deformed, and the stress distribution in the pipe becomes more uniform. The average Von-Mises stress value in the deformed pipe is about $265 \mathrm{MPa}$. 


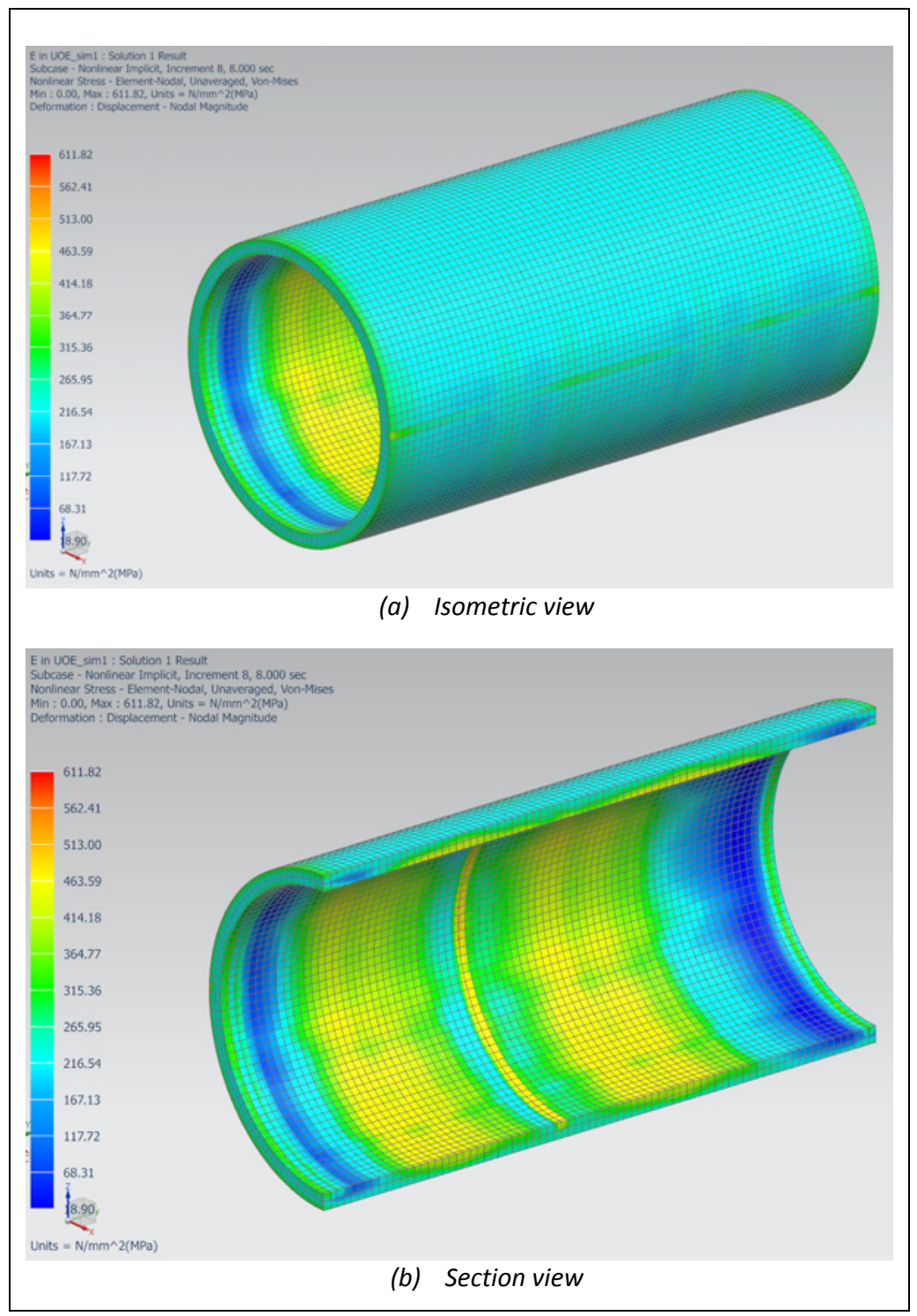

Fig. 12 Von-Mises stresses in the pipe after the fourth expansion step

(C) Siemens 2019. Reprinted with permission

FEA results indicate that a critical region is developed in the pipe internal surface after the third expansion step, as illustrated in Figure 12b. Unlike the previous transition regions, the new critical region is located at the opposite end of the expansion step. The Von-Mises stress in this region reaches a value of $611.82 \mathrm{MPa}$ on the internal surface. The stress values then decrease up to about (203.94 MPa) as they approach the external surface. It can be seen from Figures 10 and 13 that the formation of the new high stressed region is caused by the expander die profile at the end of the Flat Length. 


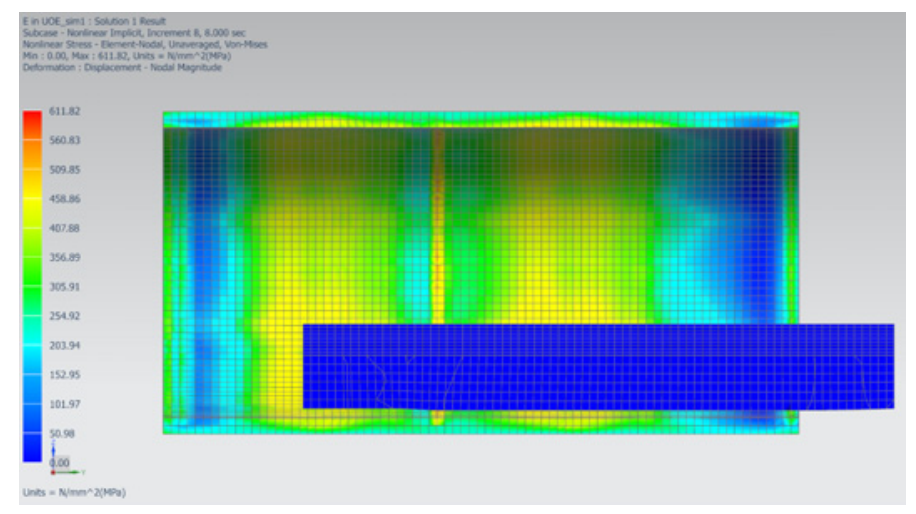

Fig. 13 Transition region in the third expansion step

(C) Siemens 2019. Reprinted with permission

After the fourth expansion step, a new transition region is developed in the pipe like the one in the previous step. The Von-Mises stress distribution is uniform across the circumference, and the average value of the Von-Mises stress in the pipe is $265 \mathrm{MPa}$.

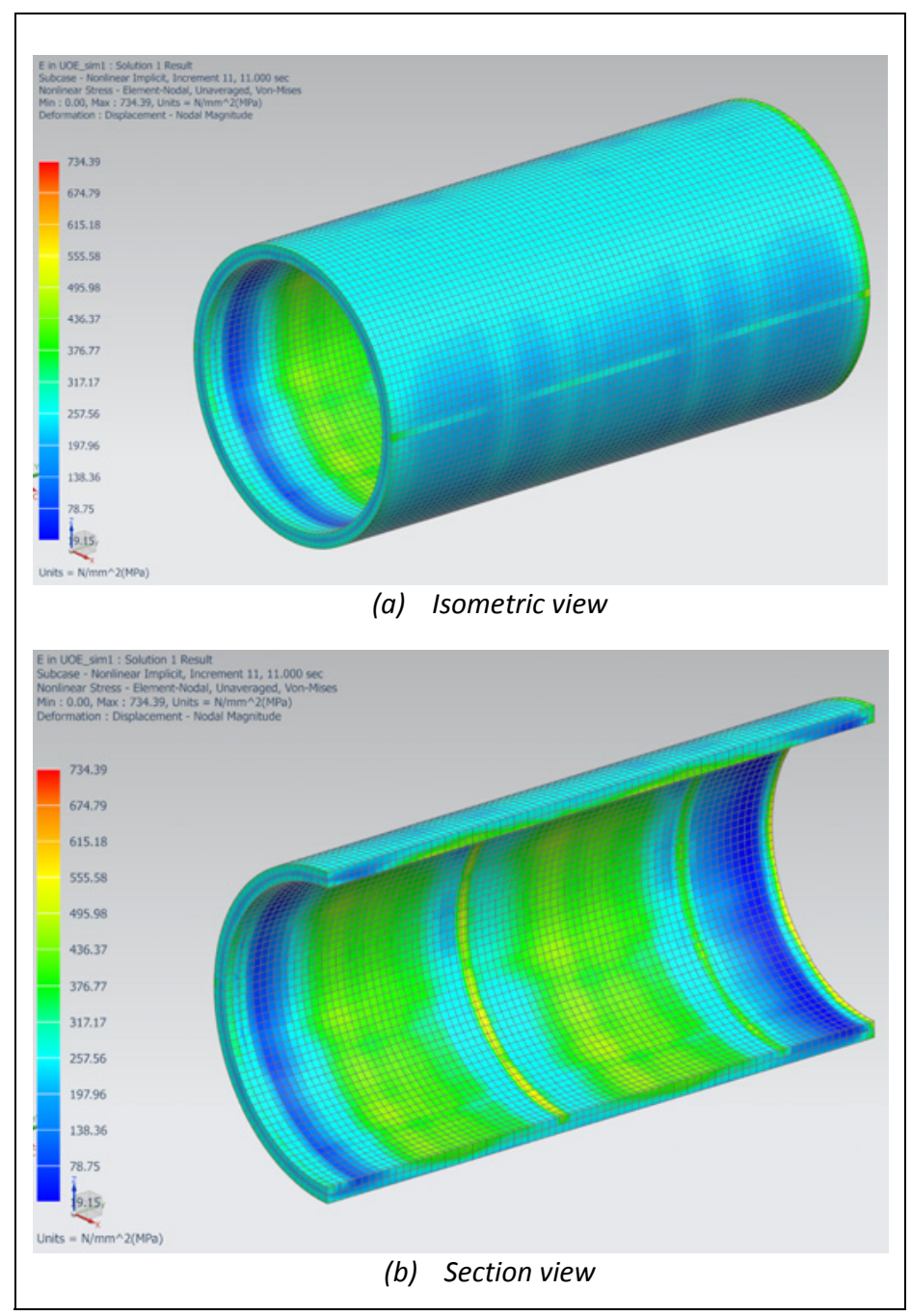

Fig. 14 Von-Mises stresses in the pipe after the fourth expansion step

(C) Siemens 2019. Reprinted with permission 
Figure 15 represents the results obtained for the Von-Mises stresses in the pipe after performing the expansion operation. Von-Mises stress was determined using a sufficiently appropriate dense number of points across the pipe circumference. Two sets of measurement were taken; the first measurement from the normal region, and the second from the transition region. It can be seen from Figure 15 that the Von-Mises stresses in both regions have a similar distribution, but the Von-Mises stresses in the transition region are greater than those in the normal region. The maximum Von-Mises stress in the normal region and the transition region are 229.391 $\mathrm{MPa}$ and 425.820 $\mathrm{MPa}$, respectively, while the minimum Von-Mises stress in the normal region and the transition region are $150.783 \mathrm{MPa}$ and $358.549 \mathrm{MPa}$, respectively. The average difference between both results is estimated to be $75.728 \%$.

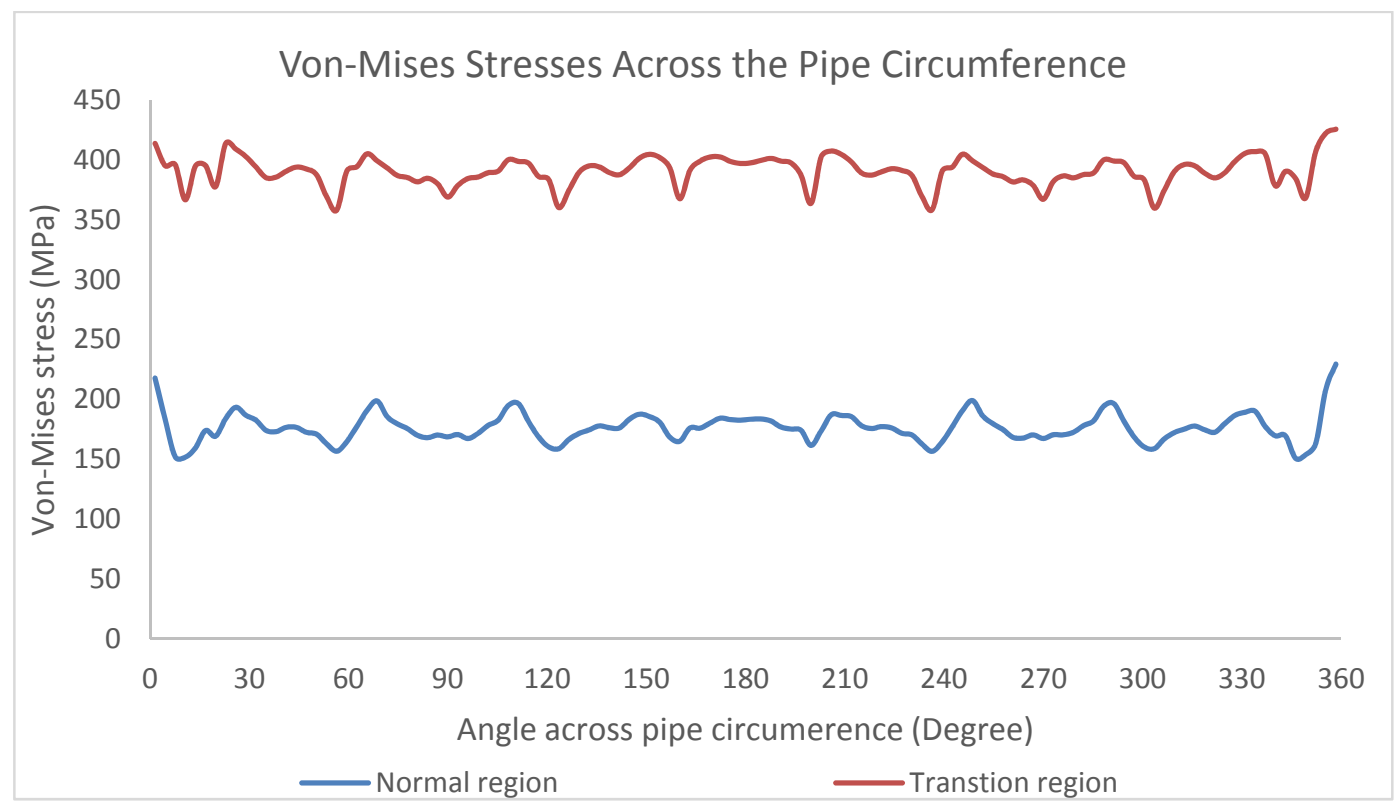

Fig. 15 Von-Mises stresses in the normal region and transition region

\subsubsection{EFFECT ON MECHNICAL EXPANDER DIES}

Figure 16 shows the Von-Mises contact stress distribution across the mechanical expander dies during the first expansion step. Figure 16 shows that the Von-Mises stress distribution along the longitudinal direction is not uniform, and the average Von-Mises stress value across the expander die is about $84.645 \mathrm{MPa}$. Also, high-stress concentration areas are developed in the region in contact with the pipe end profile and die edges. The Von-Mises stress at these regions reaches values up to $345.91 \mathrm{MPa}$. 


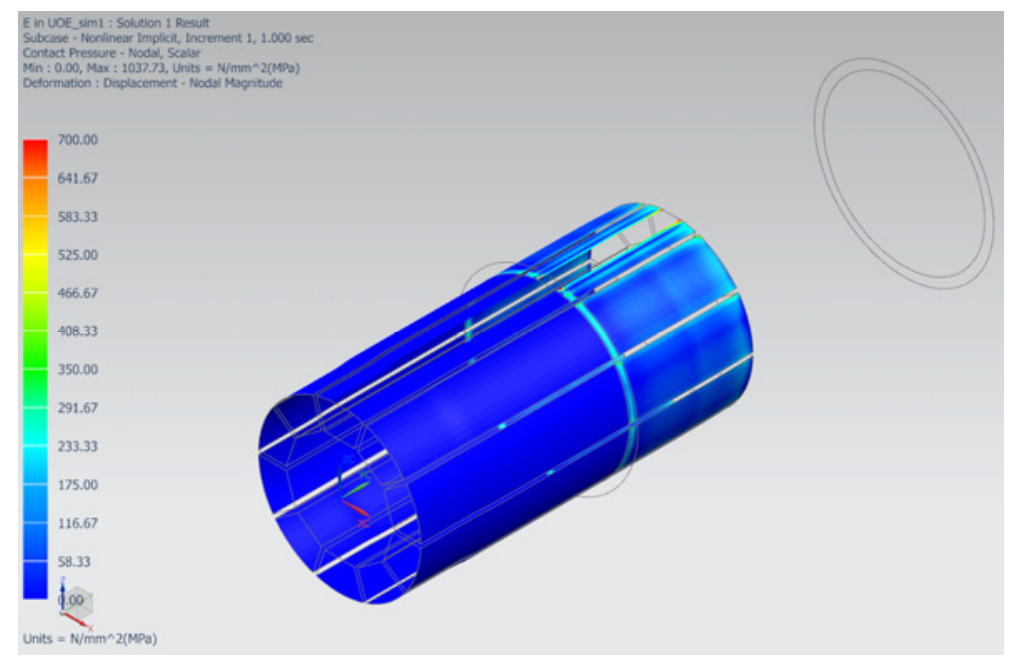

Fig. 16 Von-Mises stresses in expander die during the first expansion step

(C) Siemens 2019. Reprinted with permission

Furthermore, the maximum stresses are observed on the weld seam gap edges located on the top die, as shown in Figure 17. The Von-Mises stress at this region reaches a maximum value of 1037.729 MPa due to the simplification made on the top die model as fillets on the weld seam gap were neglected.

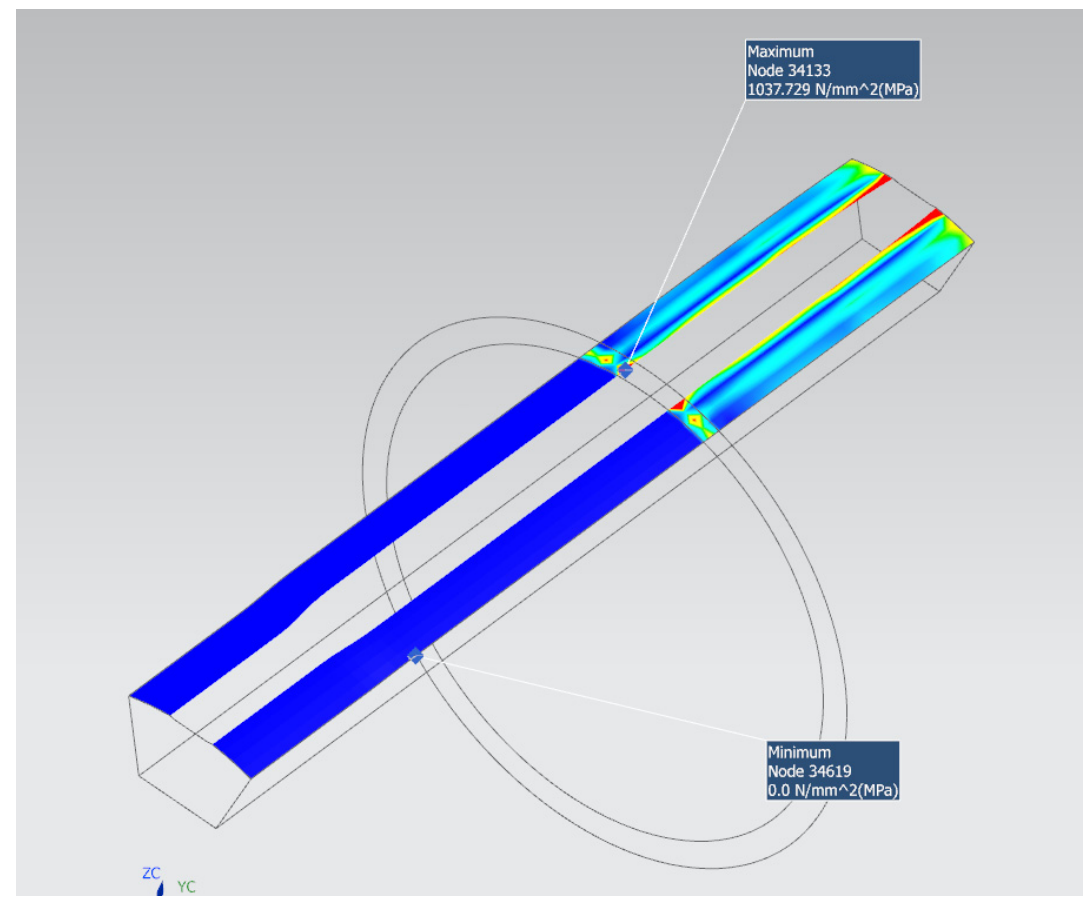

Fig. 17 Von-Mises stresses in mechanical expander top die

(C) Siemens 2019. Reprinted with permission

During the second expansion step, the Von-Mises stress distribution is not uniform along the longitudinal direction, and the average Von-Mises stress value is around 79.620 MPa. High-stress concentration areas are developed on the expander Flat Length end and die edges, as demonstrated in Figure 18. The Von-Mises stress at these regions reaches values up to $525 \mathrm{MPa}$. 


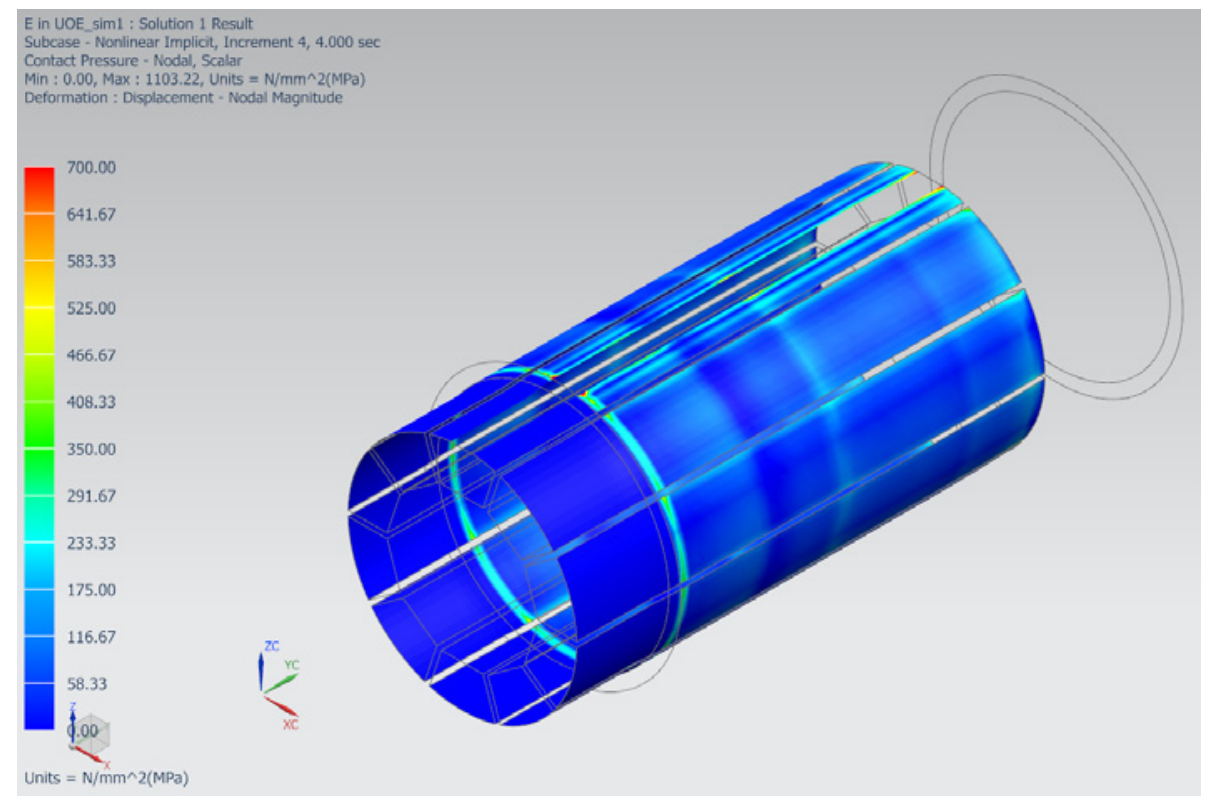

Fig. 18 Von-Mises stresses in expander die during the second expansion step

(C) Siemens 2019. Reprinted with permission

During the third expansion step, the Von-Mises stress distribution is not uniform in the longitudinal direction, and the average value is $76.980 \mathrm{MPa}$. High-stress concentration, with similar values as the previous, expansion steps is located at the pipe end profile, the expander die Flat Length end and die edges, as demonstrated in Figure 19.

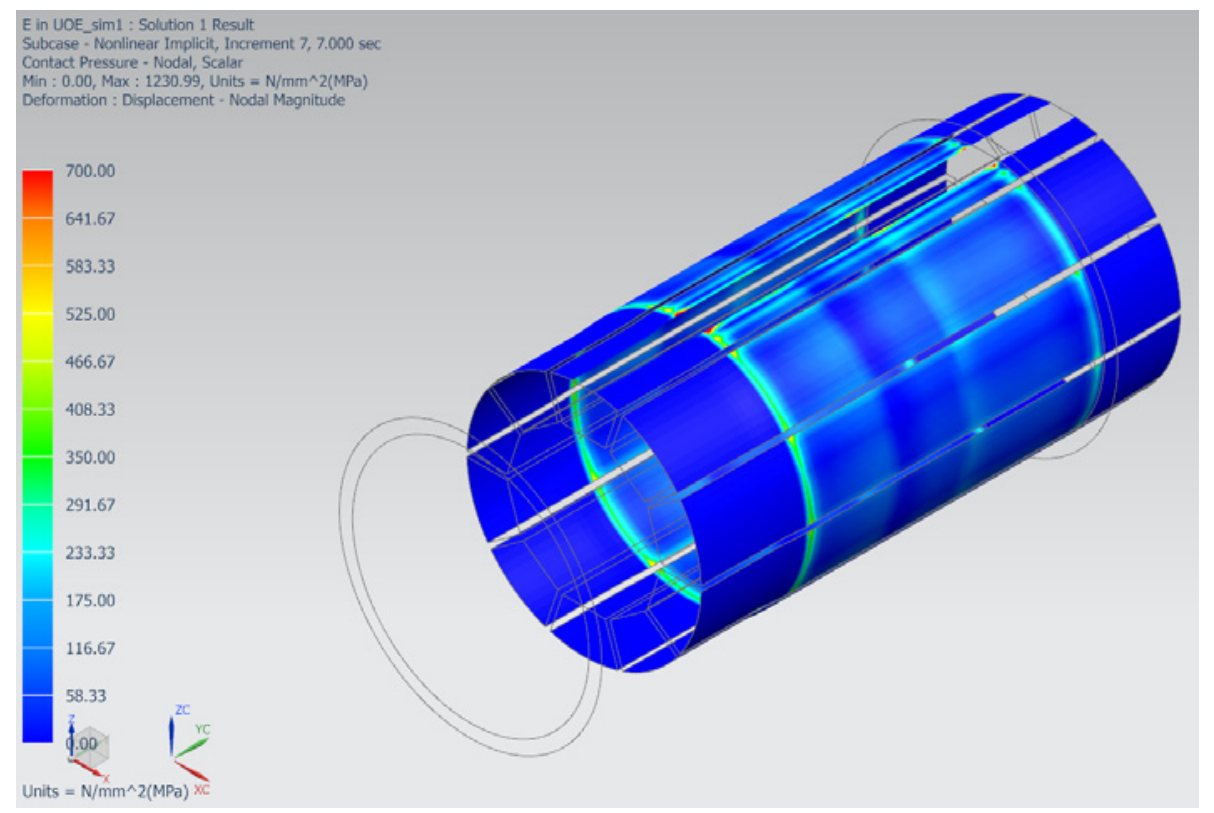

Fig. 19 Von-Mises stresses in expander die during the third expansion step

(C) Siemens 2019. Reprinted with permission

During the four expansion steps, the Von-Mises stress distribution is not uniform along the longitudinal direction, and the average Von-Mises stress value is around $78.618 \mathrm{MPa}$. High- 
stress concentration, with similar values as in the previous expansion step, is located on the pipe end profile, the expander die Flat Length end and die edges, as demonstrated in Figure 20.

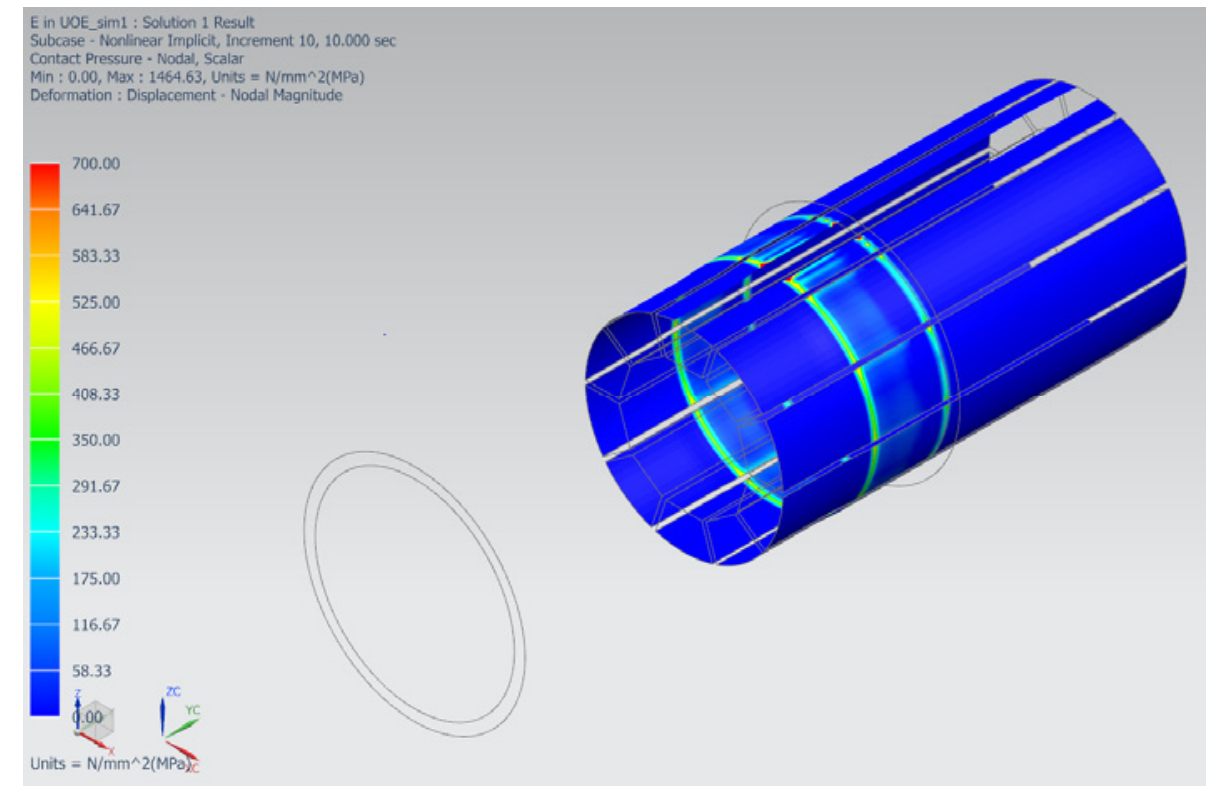

Fig. 20 Von-Mises stresses in expander die during the fourth expansion step

(C) Siemens 2019. Reprinted with permission

\subsection{SECOND 3D FEA (MECHANICAL EXPANDER DIES OPTIMISATION)}

This study involved creating five FEA simulations using similar arrangements as the first analysis. However, the expander dies radius in each simulation was varied, as shown in Table.2. Since the aim of the study is to explore the benefit of optimising the expander dies on the finished pipe shape, the time increment in the Enforced Displacement Constraint boundary condition has been reduced to two-time increments to perform one expansion step.

Table 2 FEA 2 configuration

\begin{tabular}{ccccc}
\hline Model (1) & Model (2) & Model (3) & Model (4) & Model (5) \\
\hline $\begin{array}{c}\text { Original die radius } \\
\text { size }\end{array}$ & Die radius reduced & Die radius reduced & Die radius reduced & Die radius reduced \\
by 1\% & by 2\% & by 3\% & by 4\% \\
\hline
\end{tabular}

\subsection{RESULTS}

\subsubsection{PIPE CROSS-SECTION}

Figure 21 is the displacement results obtained for each of the five models. Figure $21 \mathrm{~b}$ shows that model (2) has produced a more uniform cross-section compared to model (1) as it allowed the pipe to plastically deform and stretch more evenly in the circumferential direction. However, reducing the expander die radius further will not additionally improve the pipe shape, as demonstrated in Figure 21c. 


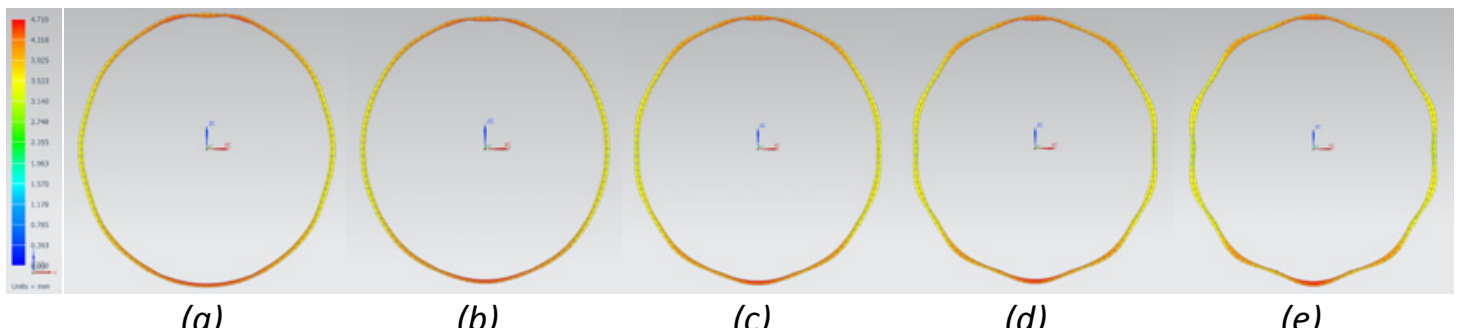

(a)

(b)

(c)

(d)

(e)

Fig. 21 Pipe cross-section in a) model (1), b) model (2), c) model (3), d) model (4), and e) model (5)

(C) Siemens 2019. Reprinted with permission

Reducing the expander radius by (2\%) in model 3 results in the formation of wave patterns and concavities on the external and internal surfaces of the pipe. The scale of these patterns and concavities increases with further reduction in die radius as the case with models 4 and 5 . Based on the above observation, model 2 has produced the optimum cross-section.

\subsubsection{WALL THICKNESS VARIATION}

Figure 22 illustrates the results for wall thickness variation in model 1 . The results showed fluctuation in wall thickness values. The highest and lowest wall thickness values in model 1 were $25.075 \mathrm{~mm}$ and $24.919 \mathrm{~mm}$, respectively. The mean wall thickness was estimated to be $25.027 \mathrm{~mm}$, and the standard deviation between the wall thickness variations was $0.034 \mathrm{~mm}$.

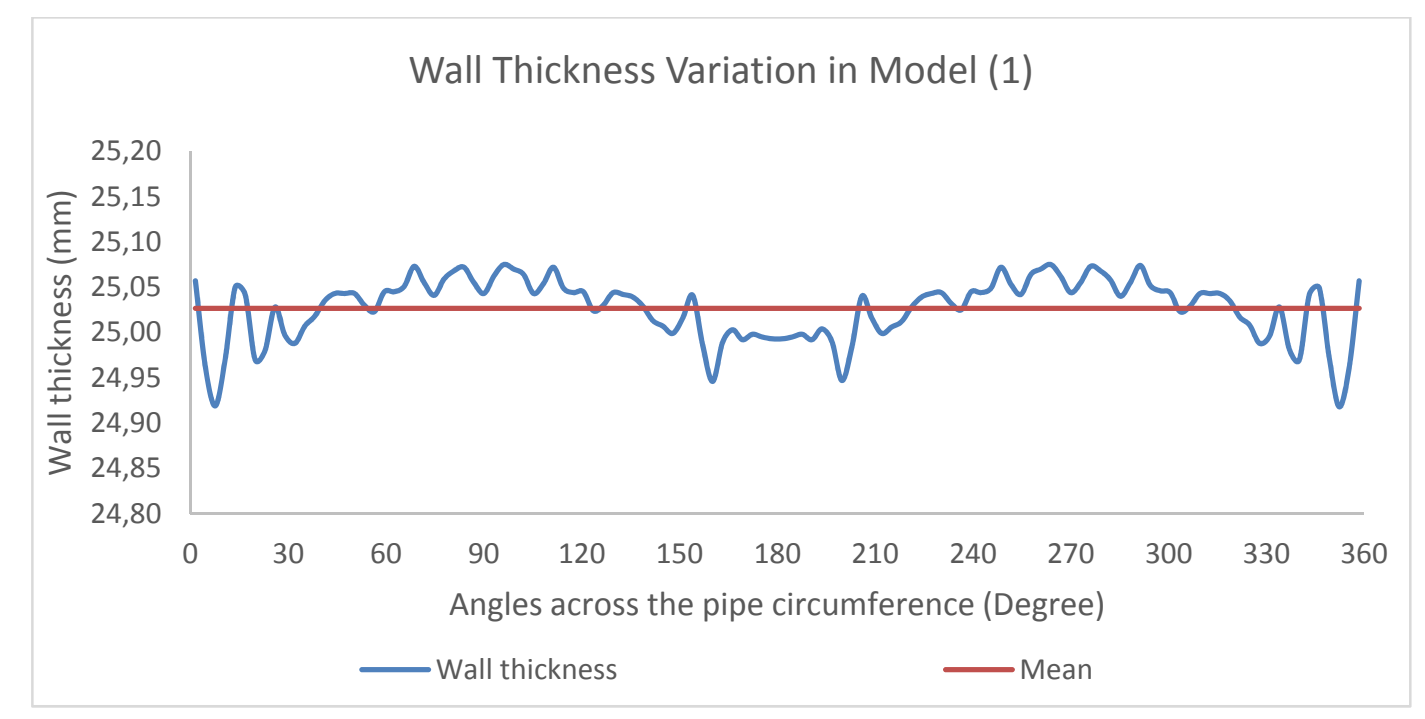

Fig. 22 Wall thickness variation in the model (1)

In model 2, the wall thickness variation is like model 1 . However, large oscillations are observed in some regions, as illustrated in Figure 23. As seen from Figure 23, the highest and lowest wall thicknesses are $25.096 \mathrm{~mm}$ and $24.20 \mathrm{~mm}$, respectively. The mean wall thickness in model 2 was estimated to be $25.030 \mathrm{~mm}$, and the standard deviation between the wall thickness values was $0.037 \mathrm{~mm}$. 


\section{Wall Thickness Variation in Model (2)}

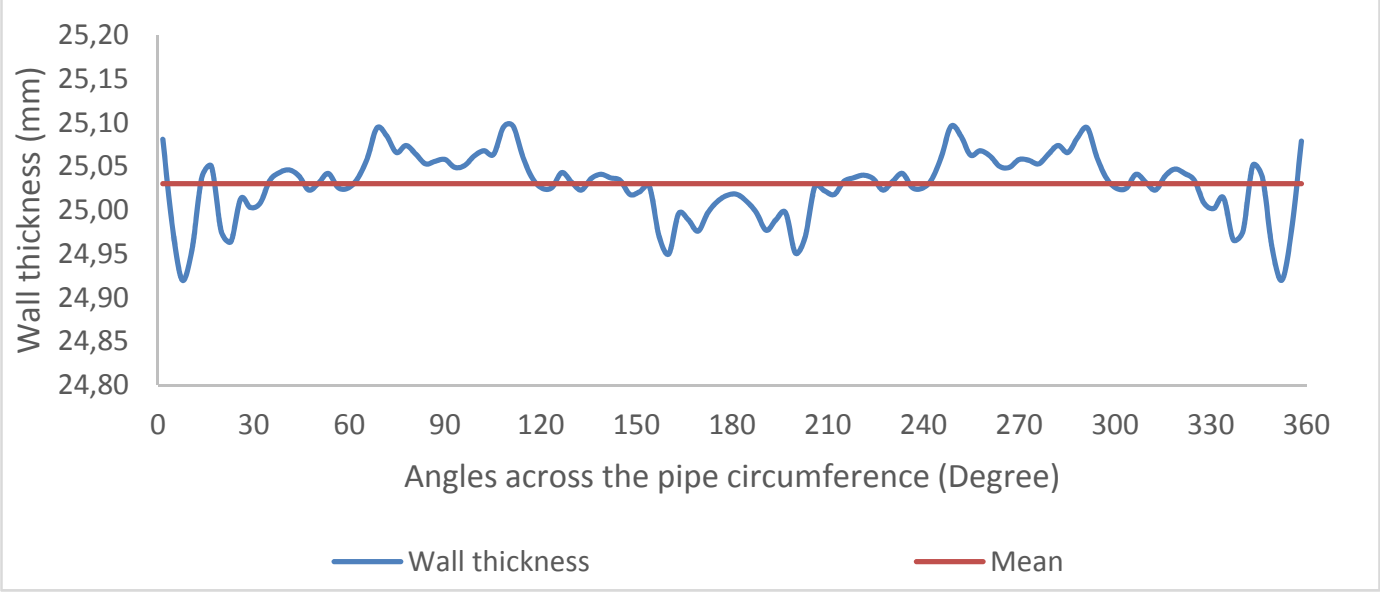

Fig. 23 Wall thickness variation in the model (2)

The wall thickness variation in model 3 is different from that in model 1. The graph in Figure 24 shows larger fluctuation with a more regular pattern compared to Figure 22. The highest wall thickness was $25.118 \mathrm{~mm}$, and the lowest $24.922 \mathrm{~mm}$. The mean value for the wall thickness was estimated to be $25.033 \mathrm{~mm}$, and the standard deviation between the wall thickness variations was $0.044 \mathrm{~mm}$.

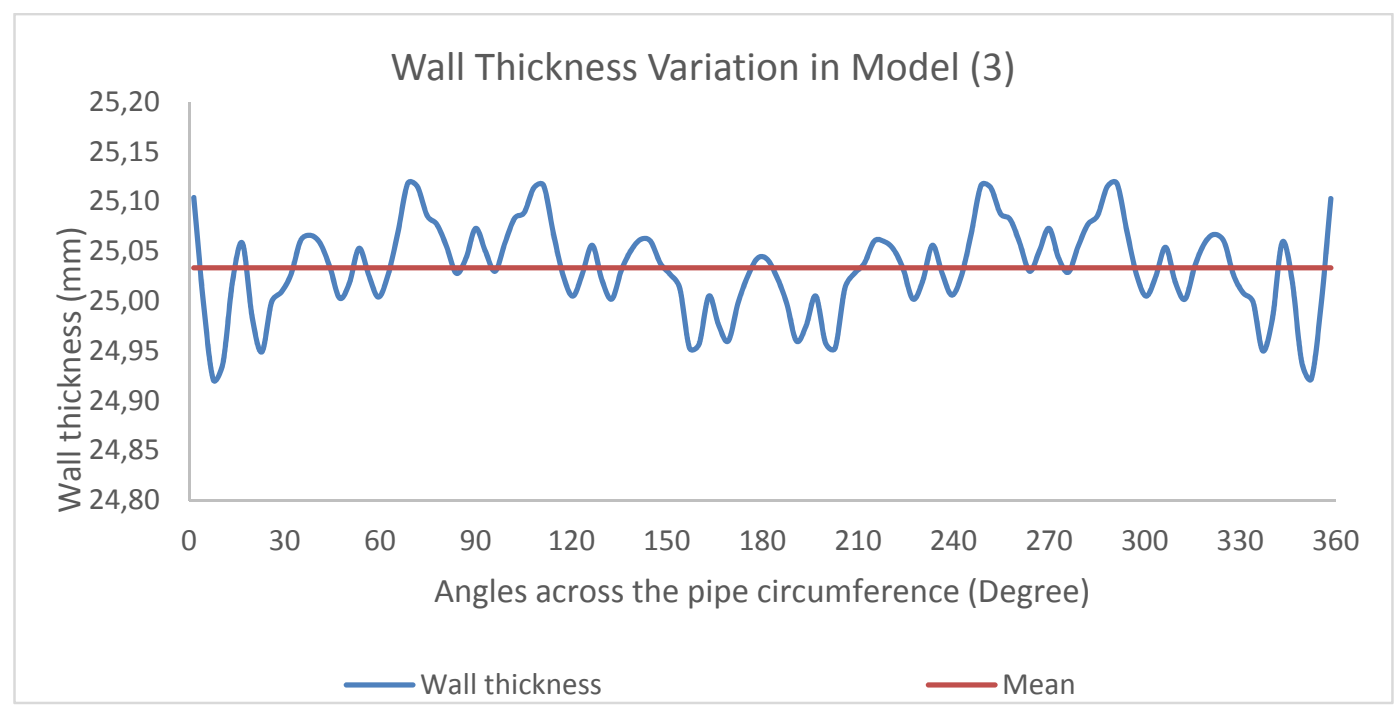

Fig. 24 Wall thickness variation in the model (3)

The wall thickness variation in model 4 is like model 3 . However, large oscillations are observed as patterns become more regular, as illustrated in Figure 25. The highest wall thickness was $25.147 \mathrm{~mm}$, and the lowest $24.924 \mathrm{~mm}$. The mean value for the wall thickness was estimated to be $25.036 \mathrm{~mm}$, and the standard deviation between the values of wall thickness was $0.056 \mathrm{~mm}$. 


\section{Wall Thickness Variation in Model (4)}

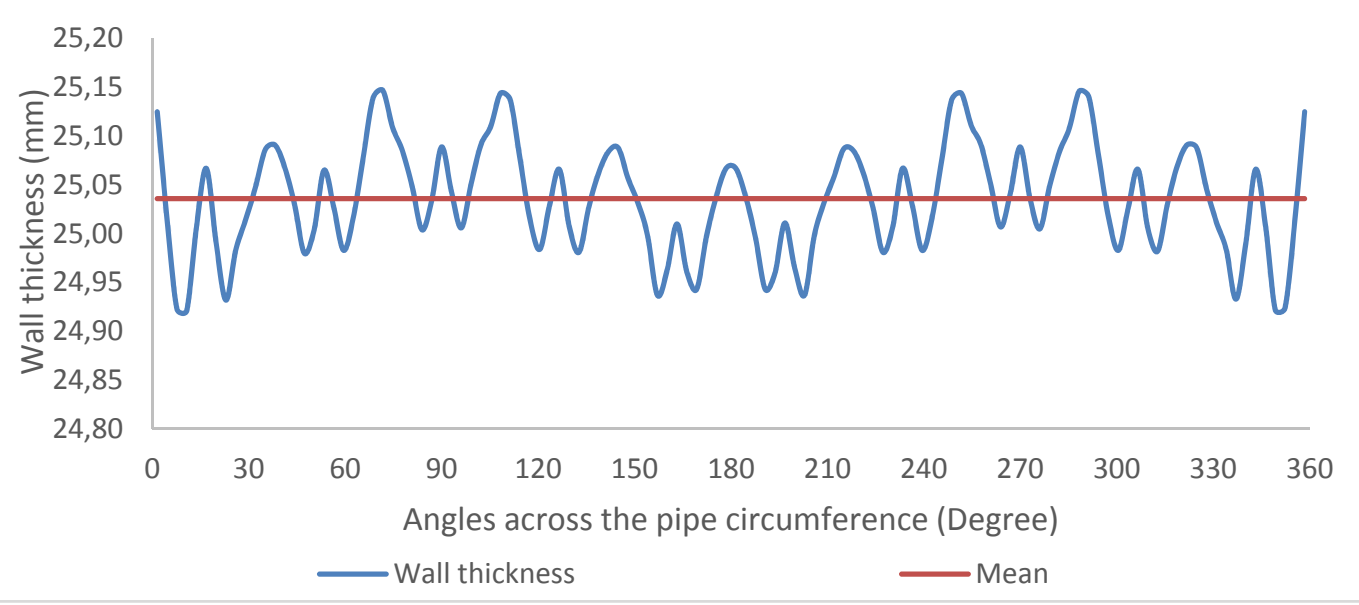

Fig. 25 Wall thickness variation in the model (4)

In model 5 , the oscillations in wall thickness values are larger than in the model 4 . The highest and lowest wall thickness in model 5 was $25.175 \mathrm{~mm}$ and $24.910 \mathrm{~mm}$, respectively. The mean wall thickness value was $25.038 \mathrm{~mm}$, and the standard deviation between the values of wall thickness was $0.069 \mathrm{~mm}$.

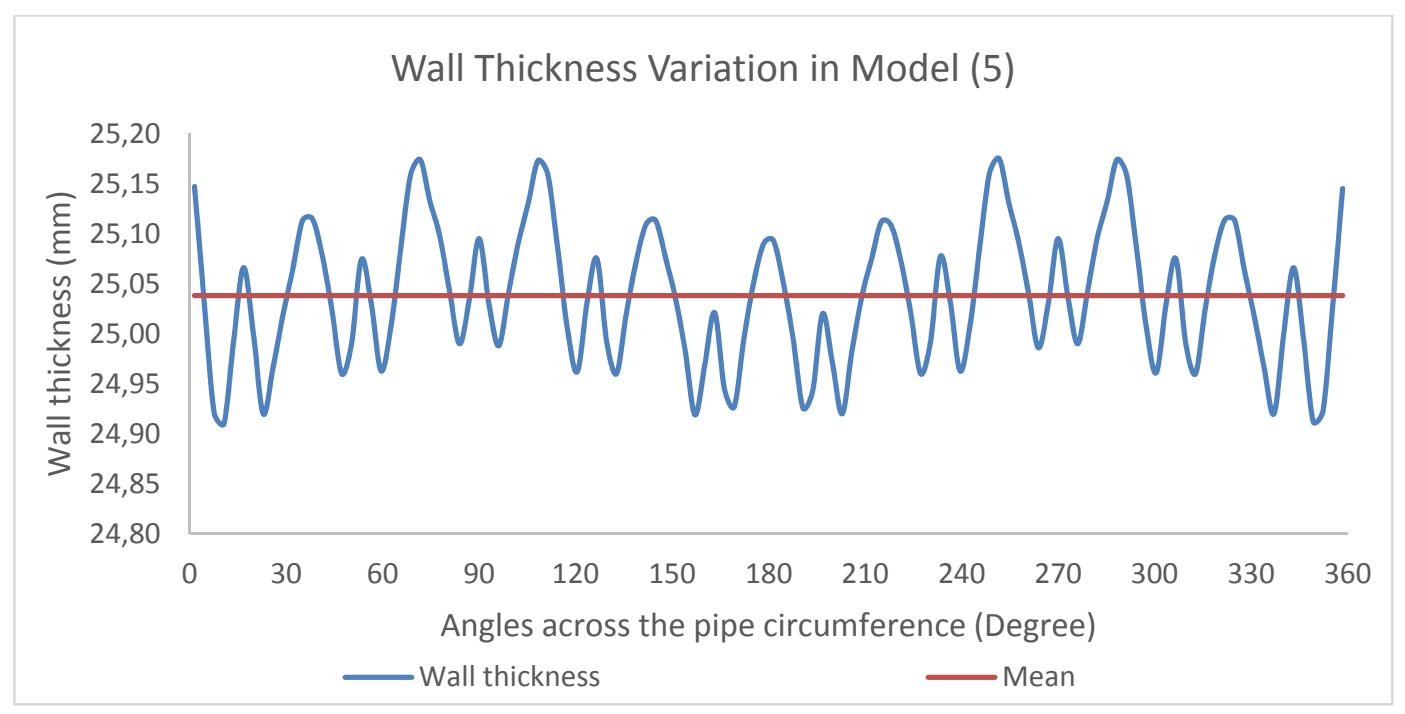

Fig. 26 Wall thickness variation in the model (5)

Based on the above observation, model 1 with the original die radius has produced more uniform wall thickness compared to the other models although, model 2 showed similar wall thickness variation with a slight increase of $8.45 \%$ in the standard deviation between the values of wall thickness.

\subsubsection{VON-MISES STRESS ON PIPE INTERNAL DIAMETER ID}

Figure 27 shows the Von-Mises stress distribution in model 1. Figure 27 shows fluctuation in the values of the Von-Mises stress, with the highest of $220.410 \mathrm{MPa}$ and the lowest of $138.377 \mathrm{MPa}$. 
The mean value for the stress was $165.930 \mathrm{MPa}$, and the standard deviation between the VonMises stress values 13.144 MPa.

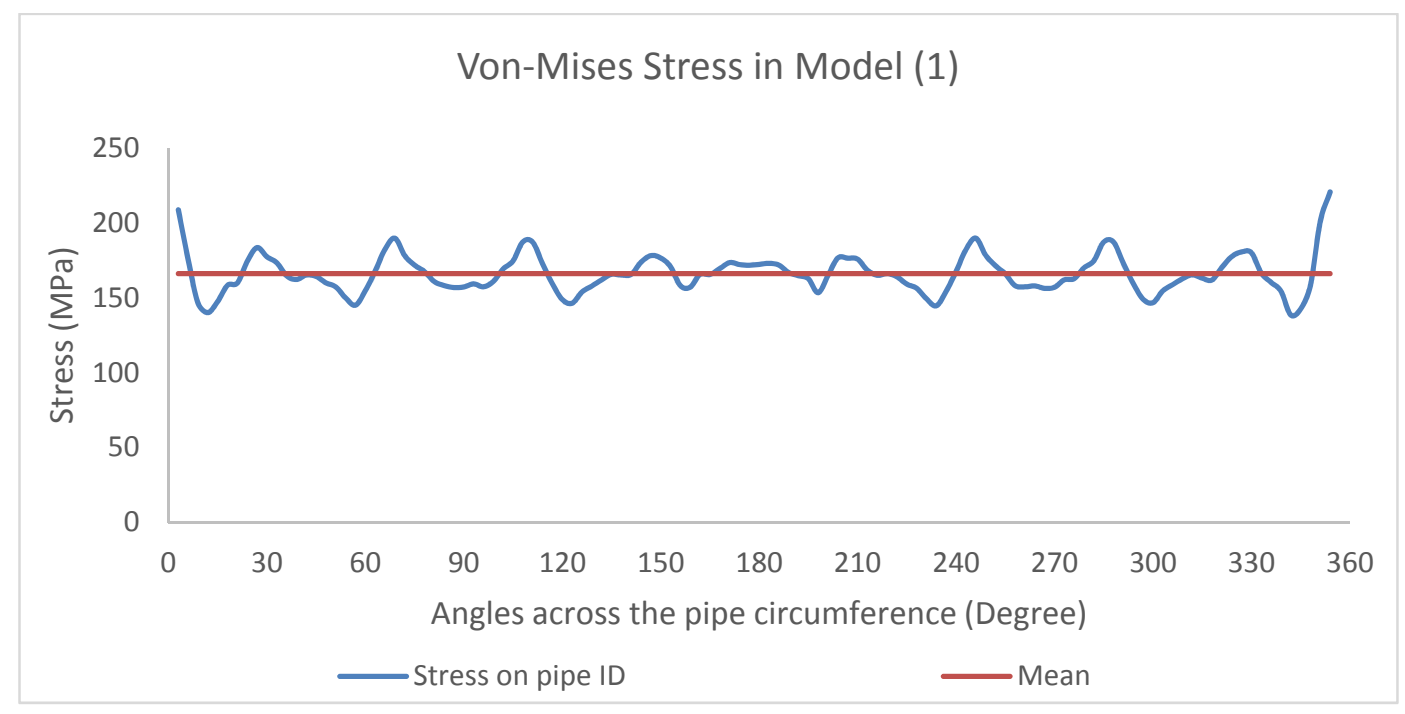

Fig. 27 Von-Mises stress in the model (1)

Figures 28, 29, 30, 31, and 32 illustrate the Von-Mises stress distribution in the remaining models.

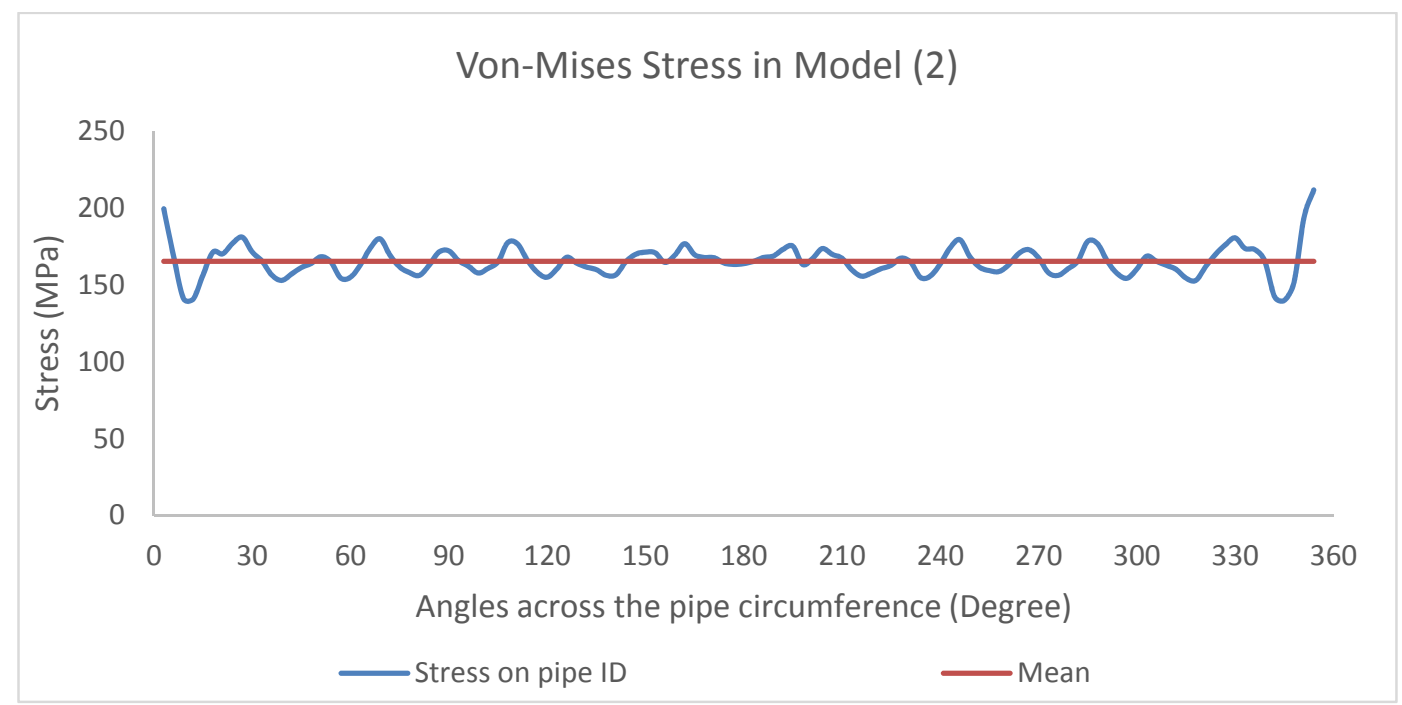

Fig. 28 Von-Mises stress in the model (2) 


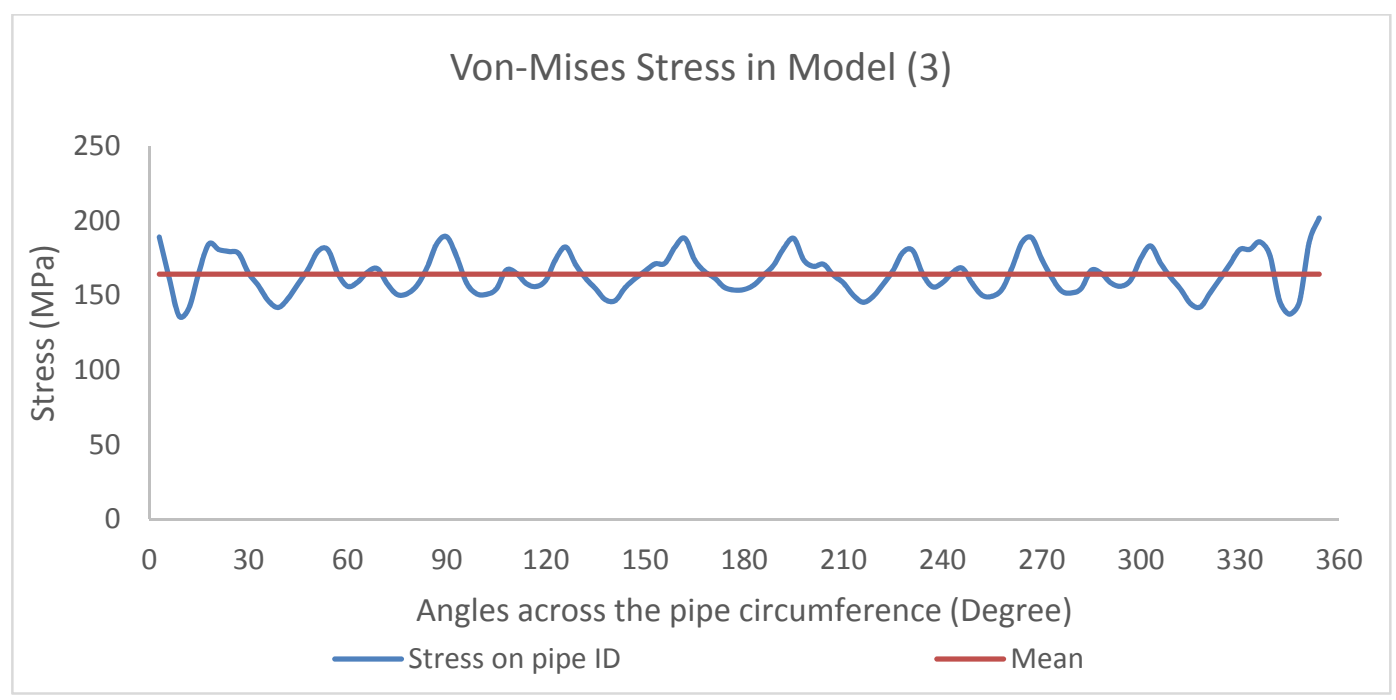

Fig. 29 Von-Mises stress in the model (3)

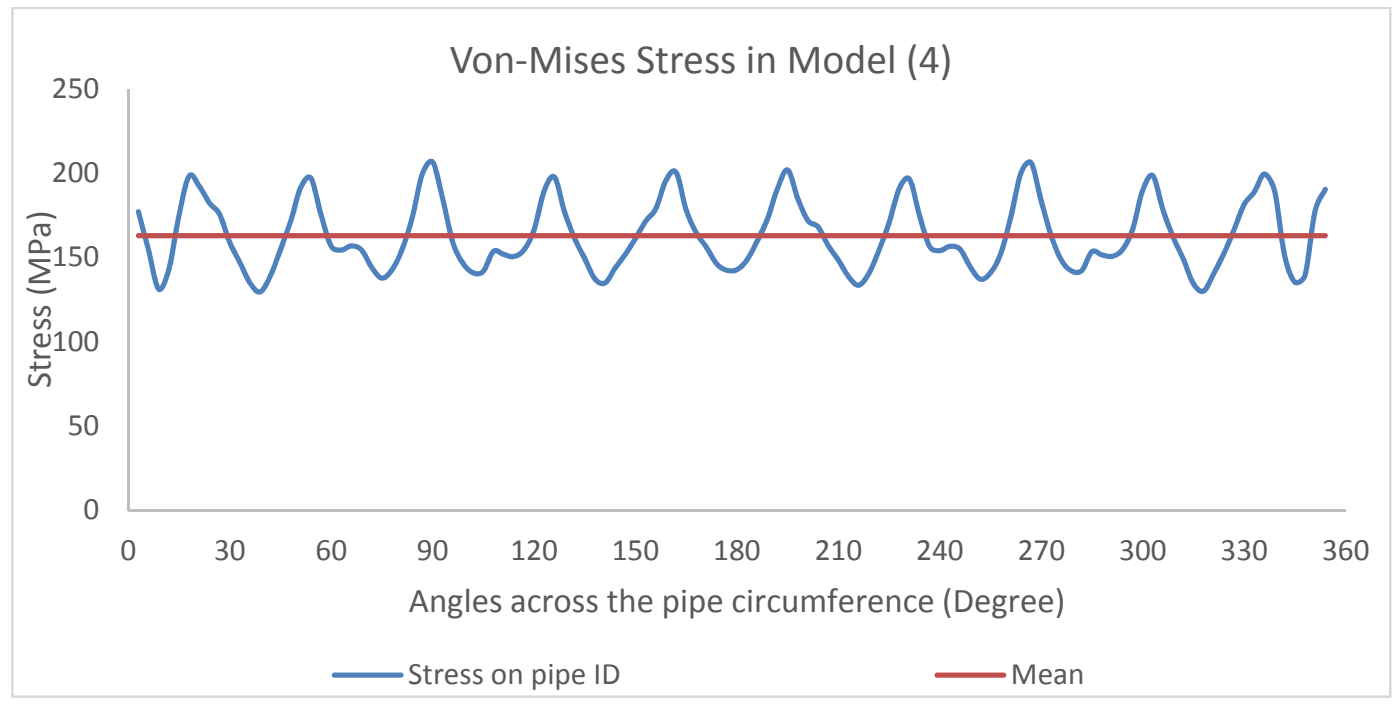

Fig. 30 Von-Mises stress in the model (4)

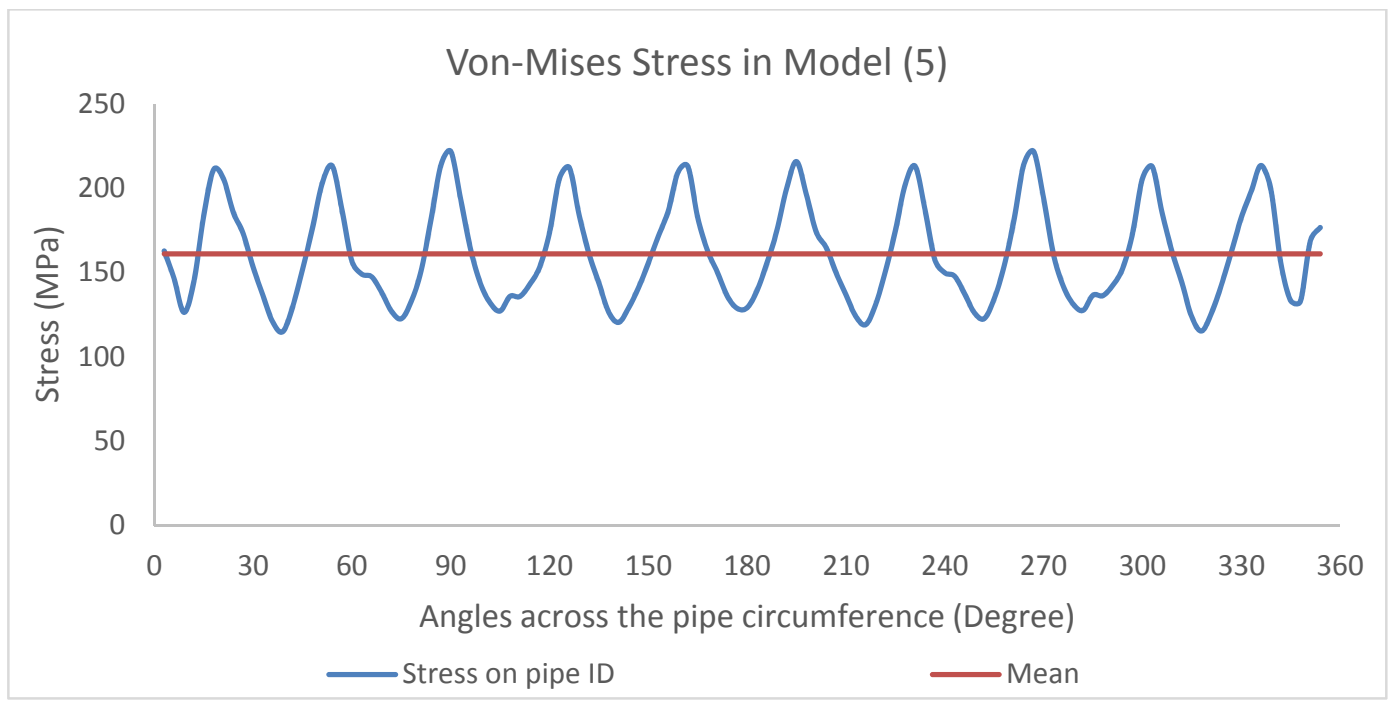

Fig. 31 Von-Mises stress in the model (5) 


\subsubsection{EFFECT ON MECHANICAL EXPANDER DIES}

Figure 32 shows the simulation results obtained for the Von-Mises stress distribution in the expander dies for each of the five models. Simulation results for model 1 show a high-stress concentration on the die edges, as illustrated in Figure 32a. The average stress value in these regions is estimated to be $159.782 \mathrm{MPa}$. In model 2, the stress distribution appears to be much more improved and uniform across the dies top surface compared to model 1, as shown in Figure 33b. The regions previously characterised by high-stress concentration are reduced to an average value of $118.761 \mathrm{MPa}$ which is a $29.45 \%$ decrease compared to model 1 . In addition, the stress concentration in model 3, model 4 , and model 5 are further reduced to an average value of 79.532 $\mathrm{MPa}, 52.757 \mathrm{MPa}$, and 46.117 $\mathrm{MPa}$, respectively.

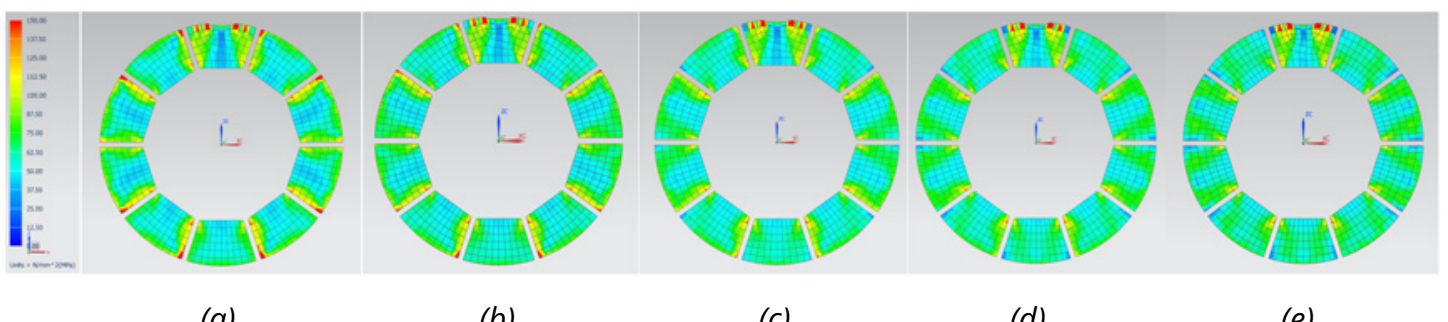

(a)

(b)

(c)

(d)

(e)

Fig. 32 a) Dies in model (1), b) dies in model (2), c) dies in model (3), d) dies in model (4), e) dies in model (5)

(C) Siemens 2019. Reprinted with permission

However, Figure 32c signifies that reducing the expander dies radius further to a value beyond $2 \%$ can increase the Von-Mises stress distribution in the mid-section of the expander dies, as illustrated in Figure $32 \mathrm{~d}$ and Figure 32e. When the die radius is reduced, the surface contact between the expander dies and the pipe internal surface decreases, and undesired deformation across the pipe circumference is produced. Therefore, based on the above observation, model 3 has the most suitable die size as it provides a balance between pipe shape and stresses on the expander dies.

\section{CONCLUSION}

The expansion stage in the UOE pipe manufacturing process was investigated by adopting a Nonlinear Finite element analysis approach. The effect of expansion operation on the final pipe geometry and mechanical expander dies integrity was considered. Two FEA studies were carried out. The first FEA involved simulating the expansion stage in the UOE manufacturing process to examine the effect of the expansion stage on the finished pipe shape and studied the stresses in the pipe and mechanical expander dies. This study highlighted that the expansion operation affects the finished pipe geometry as it results in the formation of wave patterns and concavities on the pipe external and internal surfaces that introduce wall thickness variations across the pipe circumference. The study also revealed that the value of pipe ovality is not equal in the longitudinal direction since, after expansion, it ranges between $0.034 \%$ to $0.055 \%$. In addition, the study showed that after expansion, transition regions are developed within the pipe with similar stress distribution to the normal regions. However, the stresses in the transition region is found to be $75.728 \%$ greater than those in the normal region. Furthermore, the study revealed that the Von-Mises stresses, the mechanical expander dies experience 
during the expansion are about $10.26 \%$ lower than the material's yield strength. However, higher Von-Mises stresses were found on the weld seam area with stress a value of 1037.729 $M P a$, but this value was not accurate since the fillets on the weld seam were neglected to simplify the simulation. The second FEA study involved carrying out five simulations to investigate the benefit of optimising the mechanical expander dies design on the finished pipe shape. This study showed that reducing the expander die radius by $1 \%$ in model 2 significantly improved the pipe shape as it produced a more uniform cross-section compare to the original expander die size in model 1 . The study also revealed that model 2 reduced the high-stress concentration regions located on the expander die edges by $29.45 \%$ lower than model 1 . Furthermore, the study showed that reducing the expander die radius beyond $2 \%$ results in increasing the Von-Mises stress distribution in the mid-section of the expander dies., This results in the formation of wave patterns and concavities on the pipe external and internal surfaces. The scale of these patterns and concavities increases with further reduction in die radius, as the case with model 4 and model 5 .

\section{ACKNOWLEDGMENTS}

The authors would like to thank Liberty Steel 42-inch SAW Pipe Mill at Hartlepool for providing them an opportunity to carry out this study. The authors would like to extend their thanks to Teesside University, which allows them to access the specialist software. As such, the finite element results are generated using $\mathrm{NX}^{\mathrm{TM}}$ software, version 10, and a list of relevant Siemens trademarks can be found here:

https://www.plm.automation.siemens.com/global/en/legal/trademarks.html

\section{REFERENCES}

[1] M.D. Herynk, S. Kyriakides, A. Onoufriou, H.D. Yun, Effects of the UOE/UOC pipe manufacturing processes on pipe collapse pressure, International Journal of Mechanical Sciences, Vol. 49, No. 5, pp. 533-553, 2007.

https://doi.org/10.1016/i.ijmecsci.2006.10.001

[2] S. Kyriakides, E. Corona, Mechanics of Offshore Pipelines : Volume 1 Buckling and Collapse, $1^{\text {st }}$ ed. Oxford: Elsevier Science \& Technology, 2007.

[3] O. Fyrileiv, O. Aamlid, A. Venås, L. Collberg, Deepwater pipelines - status, challenges and future trends, Journal of Engineering for the Maritime Environment, Vol. 227, No. 4, pp. 381-395, 2013. https://doi.org/10.1177/1475090212450659

[4] M. Langhelle, Pipelines for Development at Deep Water Fields, Master Thesis, Marine and Subsea Technology, University of Stavenger, 2011.

[5] Y. Tianyuan, B. Liu, M. Duan, Z. Guo, C. An, Numerical simulation of the buckle propagation problem in deepwater pipelines, The 2015 World Congress on Advances in Structural Engineering and Mechanics (ASEM15), Incheon, Korea, 2015.

[6] R.G. Toscano, Collapse and post-collapse behavior of steel pipes under external pressure and bending, Application to deep water pipelines, Doctoral Thesis, Universidad de Buenos Aires, Argentina, 2009. 
[7] G. Chatzopoulou, Finite Element Simulation of UOE Pipe Manufacturing Process and its Effect on Offshore Pipeline Mechanical Behavior, Post-Graduate Diploma, University of Thessaly, 2012.

[8] B. Fallqvist, Collapse of thick deepwater pipelines due to hydrostatic pressure, Master Dissertation, Department of Solid Mechanics, Royal Institute of Technology (KTH), Stockholm, Sweden, 2009.

[9] H.-G. Hillenbrand, M.K. Graef, J. Groß-Weege, G. Knauf, U. Marewski, Development of line pipe for deep water applications, The Twelfth International Offshore and Polar Engineering Conference, 26-31 May, Kitakyushu, Japan, International Society of Offshore and Polar Engineers, 2002.

[10] R. Freeman, Research nears deepwater intercontinental gas pipeline, Oil \& Gas Journal, Vol. 109, No. 19, pp.114, 2011.

[11] G. Palumbo, L. Tricarico, Effect of forming and calibration operations on the final shape of large diameter welded tubes, Journal of Materials Processing Technology, Vol. 164165, pp. 1089-1098, 2005. https://doi.org/10.1016/i.jmatprotec.2005.02.150

[12] S. Hall, Reviewing characteristics of high-thickness, small-diameter deepwater linepipe, Offshore (Tulsa), Vol. 72, No. 11, pp. 102-104, 2012.

[13] C. Wang, Z. Zhang, R. Zhai, G. Yu, J. Zhao, Cross-sectional distortion of LSAW pipes in over-bend straightening process, Thin-Walled Structures, Vol. 129, pp. 85-93, 2018.

https://doi.org/10.1016/j.tws.2018.03.016

[14] S. Kyriakides, E. Corona, F. J. Fischer, On the effect of the UOE manufacturing process on the collapse pressure of long tubes, Houston, Texas, In: Proceedings of the Offshore Technology Conference, OTC6758, 1992. https://doi.org/10.4043/6758-MS

[15] S. Kyriakides, E. Corona, F. J. Fischer, On the effect of the UOE manufacturing process on the collapse pressure of long tubes, ASME Journal of Engineering for Industry, Vol. 116, No. 1, pp. 93-100, 1994. https://doi.org/10.4043/6758-MS

[16] C. Timms, L. Mantovano, H.A. Ernst, R. Toscano, D. DeGeer, D. Swanek, M. de Souza, L.C. Chad, The Influence of the UOE Forming Process on Material Properties and Collapse of Deepwater Linepipe. Honolulu, Hawaii, USA, In: Proceedings of the ASME $200928^{\text {th }}$ International Conference on Ocean, Offshore and Arctic Engineering OMAE2009, 2009. https://doi.org/10.1115/OMAE2009-80179

[17] J. Han and J. Sun, Numerical simulation of the UOE forming process based on MSC. Marc secondary development technology, Baosteel Tech. Res, Vol. 4, No. 3, pp. 20-26, 2010. https://doi.org/10.3969/j.issn.1674-3458.2010.03.003

[18] G. Chatzopoulou, S. A. Karamanos, G. E. Varelis, Finite element analysis of UOE manufacturing process and its effect on mechanical behavior of offshore pipes, International Journal of Solids and Structures, Vol. 83, pp. 13-27, 2016. https://doi.org/10.1016/j.ijsolstr.2015.12.020

[19] M. Vathi and S. A. Karamanos, Finite Element modelling of UOE pipe manufacturing process. Volos, Greece, In: Proceedings of the $7^{\text {th }}$ national conference on metal structures, 2011.

[20] E. Tsuru, J. Agate, Y. Nagata, S. Shirakami, Y. Shinohara, Forming and Buckling Simulation on High-strength UOE Pipe with Plastic Anisotropy - Nippon Steel Technical Report, No. 102, Nippon Steel, 2013. 
[21] M.A. Cavaliere, T. Turkalj, E.H. Giroldo, 3D Finite Element Analysis of Tube Expansion. In proceedings of $10^{\text {th }}$ World Congress on Computational Mechanics, Blucher Mechanical Engineering Proceedings, Vol. 1, No. 1, pp. 1860-1865, 2014.

https://doi.org/10.5151/meceng-wccm2012-18570

[22] T. Zou, D. Li, G. Wu, Y. Peng, Yield strength development from high strength steel plate to UOE pipe, Materials \& Design, Vol. 89, pp. 1107-1122, 2016.

https://doi.org/10.1016/j.matdes.2015.10.095

[23] M. Kainat, J.J. R. Cheng, M. Martens, S. Adeeb, Measurement and Characterization of the Initial Geometric Imperfections in High Strength U-ing, O-ing and Expanding Manufactured Steel Pipes, Journal of Pressure Vessel Technology, Vol. 138, pp. 021201-1 021201-11, 2016. https://doi.org/10.1115/1.4031507

[24] L.R. Lothhammer, M.R. Viotti, A. Albertazzi Jr., C.L.N. Veiga, Residual stress measurements in steel pipes using DSPI and the hole-drilling technique, International Journal of Pressure Vessels and Piping, Vol. 152, pp. 46-55, 2017.

https://doi.org/10.1016/j.ijpvp.2017.05.008

[25] D. Delistoian, M. Chirchor, UOE Pipe Numerical Model: Manufacturing Process and Von Mises Residual Stresses Resulted After Each Technological Step, ACTA Universitatis Cibiniensis, Vol. 69, No. 1, pp. 113-120, 2017.

[26] Sunny Steel, UOE Pipe, (2011). Retrieved Apr 18, 2019.

http://www.sunnysteel.com/uoe-pipe.php

[27] T. Zou, G. Wu, D. Li, Q. Ren, J. Xin, Y. Peng, A numerical method for predicting O-forming gap in UOE pipe manufacturing, International Journal of Mechanical Sciences, Vol. 98, pp. 39-58, 2015. https://doi.org/10.1016/i.ijmecsci.2015.04.006

[28] S.W. Wen, P. Hilton, D.C.J. Farrugia, Finite element modelling of a submerged arc welding process, Journal of Materials Processing Technology, Vol. 119, No. 1-3, pp. 203-209, 2001. https://doi.org/10.1016/S0924-0136(01)00945-1

[29] L.F. Fan, J.X. Yan, Y. Gao, J.B. Yun, Research on deformation characteristics of JCOE forming in large diameter welding pipe, Advances in Manufacturing, Vol. 4, No. 3, pp. 268-277, 2016. https://doi.org/10.1007/s40436-016-0154-5

[30] D.L. Logan, A First Course in the Finite Element Method, $6^{\text {th }}$ ed. Boston: Cengage Learning, 2016.

[31] C.S. Krishnamoorthy, Finite Element Analysis: Theory and Programming, $2^{\text {nd }}$ ed. New Delhi: Tata McGraw-Hill Publishing Company Limited, 1994.

[32] J. Raffo, R.G. Toscano, L. Mantovano, E.N. Dvorkin, Numerical model of UOE steel pipes: Forming process and structural behaviour, Mecánica Computacional, Vol. 26, pp. 317333, 2007.

[33] P.F. Liu, J.Y. Zheng, B.J. Zhang, P. Shi, Failure Analysis of Natural Gas Buried X65 Steel Pipeline Under Deflection Load using Finite Element Method, Materials and Design, Vol. 31, No. 3, pp. 1384-1391, 2010. https://doi.org/10.1016/j.matdes.2009.08.045

[34] Smiths, EN40B Technical Datasheet, 2019. https://www.smithmetal.com/pdf/engineering/en40b.pdf

[35] Roymech, Friction Factors, 2019. https://www.roymech.co.uk/Useful Tables/Tribology/co of frict.htm 